\title{
Lithologie, Stratigraphie und Paläoökologie des Mittelpleistozäns von Uichteritz im Markröhlitzer Tal (Lkr. Weißenfels/Sachsen-Anhalt)
}

\author{
Stefan Meng \& Stefan Wansa ${ }^{*}$
}

Keywords: Mittelpleistozän, Elster-Kaltzeit, SaaleKomplex, Mitteldeutschland, Markröhlitzer Tal, Schotterterrassen, Molluskenfauna, Paläoökologie

Zusammenfassung: Die seit ca. 100 Jahren umstrittene Flussgeschichte des Markröhlitzer Tales westlich von Weißenfels wird anhand neuer lithologischer und malakologischer Untersuchungen der pleistozänen Schichtenfolge in der Kiessandgrube Uichteritz diskutiert. Es konnten drei übereinander lagernde fluviatile Schotterkörper ausgehalten werden, die sich in Profilaufbau, Geröllzusammensetzung und Verwitterungsintensität unterscheiden. Sie sind durch Schlufflagen bzw. Altwasserablagerungen und schwemmfächerartige Sedimente voneinander getrennt. Der Untere Schotter ist frei von nordischem Material und kann nach der Höhenlage der frühen Elster-Kaltzeit zugeordnet werden, der Mittlere und der Obere Schotter wurden wahrscheinlich in der späten Elster-Kaltzeit akkumuliert. Dafür sprechen die gegenüber der Hauptterrasse um 10-15 m höhere Lage, die Bedeckung durch saaleglaziäre Bildungen (Beckenschluff, Bänderton, Grundmoräne) und die differenzierten Verwitterungsbildungen, die zudem übereinstimmend mit den Molluskengesellschaften eine spätelsterzeitliche Wärmeschwankung andeuten.

*Anschrift der Verfasser: Dipl.-Geol. Stefan Meng, Grüner Weg 3, D-18119 Warnemünde, E-Mail: vertigomeng@web.de; Dr. STEFan Wansa, Landesamt für Geologie und Bergwesen SachsenAnhalt, Postfach 156, D-06035 Halle, E-Mail: wansa@lagb.mw.lsa-net.de.
Molluskenfunde lieferten wichtige paläoökologische Informationen über die Bildungszeit der untersuchten Sedimente. Aus den vermutlich spätelsterzeitlichen Flussablagerungen sowie aus den im Hangenden folgenden saale- und weichselkaltzeitlichen Bildungen konnten diesbezüglich insgesamt 10 molluskenführende Horizonte untersucht werden. Aus den Unteren und Oberen Schottern sind bisher keine Fauneninhalte bekannt geworden.

Die wahrscheinlich spätelsterzeitlichen Molluskenfaunen charakterisieren deutlich unterscheidbare Faziesbereiche: fluviatile Schotterablagerungen der Saale, welche durch Fließgewässerarten dominiert werden, sowie Stillwassersedimente einer von der Saale isolierten Fließrinne bzw. eines Altarmbereiches, welche durch Stillgewässerarten dominiert werden. Nach der etwa 48 Arten umfassenden Gesamtfauna zu urteilen, fällt die Bildungszeit der Sedimente in eine mildere kaltzeitliche Phase. Zahlreiche gehölzliebende Arten lassen darauf schließen, dass in der Saaleaue Auenwälder entwickelt waren. Ausgesprochene Steppenelemente fehlen weitestgehend, was mit den taphonomischen Verhältnissen im Ablagerungsraum innerhalb der Saaleaue in Verbindung gebracht wird. Zwar ist die Rekonstruktion des weiteren Umfeldes wegen vermutlicher Überlieferungslücken problematisch, zumindest zeigen aber die individuenreichen Vorkommen von Offenlandelementen, dass wahrscheinlich außerhalb der Aue keine geschlossene Bewaldung vorhanden war. Für kühlere Bedingungen sprechen einige subarktischalpine sowie boreale und montane Faunen-Elemente.

Aus saalekaltzeitlichen Beckenschluffen sowie Geschiebemergeln konnten hochkaltzeitliche Molluskenfaunen nachgewiesen werden, wobei besonders 
die Vorkommen im Geschiebemergel bemerkenswert sind. Kaltzeitliche Mollusken fanden sich auch in weichselzeitlichen Lössen.

[Lithology, paleoecology and stratigraphy of the Middle Pleistocene of Uichteritz in the Markröhlitz valley (Weißenfels/Saxony-Anhalt)]

Abstract: The river history of the Markröhlitz valley has been discussed for about 100 years. New lithological and malacological studies of the Pleistocene sequence in the Uichteritz gravel and sand pit allow one to distinguish three fluvial gravel units. The fluvial gravel units are characterised by different structures, pebble assemblages and weathering. The gravel units are separated by silt layers (oxbow sediments, flow material) and alluvial fan deposits. The Lower Gravel Unit is free of Nordic pebble components and belongs to the early Elsterian. The Middle and Upper Gravel Units were accumulated probably during the late Elsterian, because they lie 10-15 m higher than the early Saalian Main Terrace and they are overlain by Saalian glacial sediments (silt, warved clay, till). The different weathering of the Middle Gravel Unit, together with the mollusc assemblages, indicate a temperate phase in the late Elsterian.

Mollusc finds provided essential palaeoecological information about the formation period of the sediments under review. A total of ten mollusc-containing horizons from the probable late Elsterian fluvial sediments and from subsequent formations in the overlying strata (Saale and Weichselian glaciations) were examined. To date no fauna contents are known from the Lower Gravel Unit and the Upper Gravel Unit.

The mollusc faunas clearly describe distinguishable facies areas: a fluviatile area with brash deposits from the Saale river that is dominated by different watercourses, and a limnic area with stillwater sediments from a flume that was isolated from river Saale, which is dominated by different stillwaters. Judging from the fauna that are found overall, and which comprise about 48 species, the formation period of the sediments can be dated in a milder glaciation phase. Numerous dendro-affine species suggest that rather extensive alluvial forests had developed in the river Saale floodplain. In the fossil record distinct steppe elements are largely missing - attributed to the taphonomic conditions in the deposition area of the Saale floodplain. Reconstruction of the larger environs outside of the floodplain is problematic due to presumed transmission gaps but a number of open-land evidences suggest that a dense forestation was unlikely. Some subarctic-alpine fauna elements, as well as boreal und mountainous fauna, suggest cooler conditions.

High glacial period mollusc faunas were evidenced in the Saalian basin silt with particularly notable deposits in boulder clay. Glacial period molluscs were also found in Weichselian loess.

\section{Einführung}

Die Erforschung des Quartärs am westlichen Rand der Leipziger Tieflandsbucht begann mit der intensiven Kartierung durch die Königlich Preußische Geologische Landesanstalt zu Beginn des 20. Jahrhunderts (SIEGERT \& Weißermel i9ia). Mit diesen Arbeiten wurde ein lehrbuchhaftes Grundgerüst quartärer Lithostratigraphie geschaffen, das WoldstedT (1950: 128) veranlasste, „die Saalelandschaft zwischen Halle und Weißenfels“ als eine „der klassischen Gegenden deutscher Eiszeitforschung" zu bezeichnen.

Die Lithostratigraphie des mitteldeutschen Quartärs beruht auf der Verzahnung von ausgedehnten fluviatilen Schotterterrassen mit weithin korrelierbaren Grundmoränen und Interglazialsedimenten. Durch umfangreiche geröllpetrographische Untersuchungen sowie die Erstellung und Auswertung von Schnitten und Isolinienplänen auf der Basis unzähliger Bohrungen und Aufschlussdokumentationen (Braunkohlentagebaue, Kiessandgruben) gelang es Schulz (i962), Knoth (1964), Ruske (i964), Eissmann (i 964, I975), Steinmüller (1976, 1982) u. a., die Terrassenstratigraphie zur tragenden Säule der Quartärstratigraphie im Saale-Mulde-Gebiet zu entwickeln.

Der Blick in die Literatur verdeutlicht, dass 
es trotz der jahrzehntelangen Forschung noch einige nicht hinreichend beantwortete Fragen gibt. Dazu gehört die nach der stratigraphischen Stellung von feuersteinführenden Schottern, die höher liegen als die frühsaalezeitliche Hauptterrasse und in isolierten Vorkommen an Saale, Unstrut und Salza seit langem bekannt sind (u. a. Schulz 1962, Ruske 1964, Eissmann 1975). Während die Schotter von Wangen am Unterlauf der Unstrut als spätelsterzeitlich eingestuft wurden (STEINMÜLLER 1982) und im Saale-Unterlauf drei stratigraphisch einordenbare Terrassen aus dem Zeitraum Spätelster bis Frühsaale nachgewiesen sind (KNOTH \& LENK 1962, КNoth 1964), ist die Altersstellung der Schotter von Uichteritz im Markröhlitzer Tal westlich von Weißenfels und Wallendorf (Saaleterrasse östlich von Merseburg) noch nicht hinreichend geklärt. Schulz (1962) hielt die
Schotter im Markröhlitzer Tal wie Siegert \& WeIsSERMel (1911) für holsteinwarmzeitlich und sprach von der „höheren mittelpleistozänen Terrasse“. Eissmann (1975) stellte sie in den „Komplex der elstereiszeitlichen Rückzugsschotter" und argumentierte mit Beschreibungen, in denen die Führung nordischen Materials betont wird, sowie mit dem Fossilgehalt, der zwar wenig über das Klima aussage, aber auf offenes Land hindeute. Steinmüller (1976) hat die Uichteritzer Schotter als glazifluviatile Nachschüttbildungen der Elster-Vereisung dargestellt.

Eng mit der stratigraphischen Problematik verbunden ist die Frage nach der zeitlichen Eingrenzung von fluviatilen Erosions- und Akkumulationsprozessen sowie nach der Klimaentwicklung im Zeitraum vom Ende der Elster-Kaltzeit bis zum ersten Vorstoß des Saale-

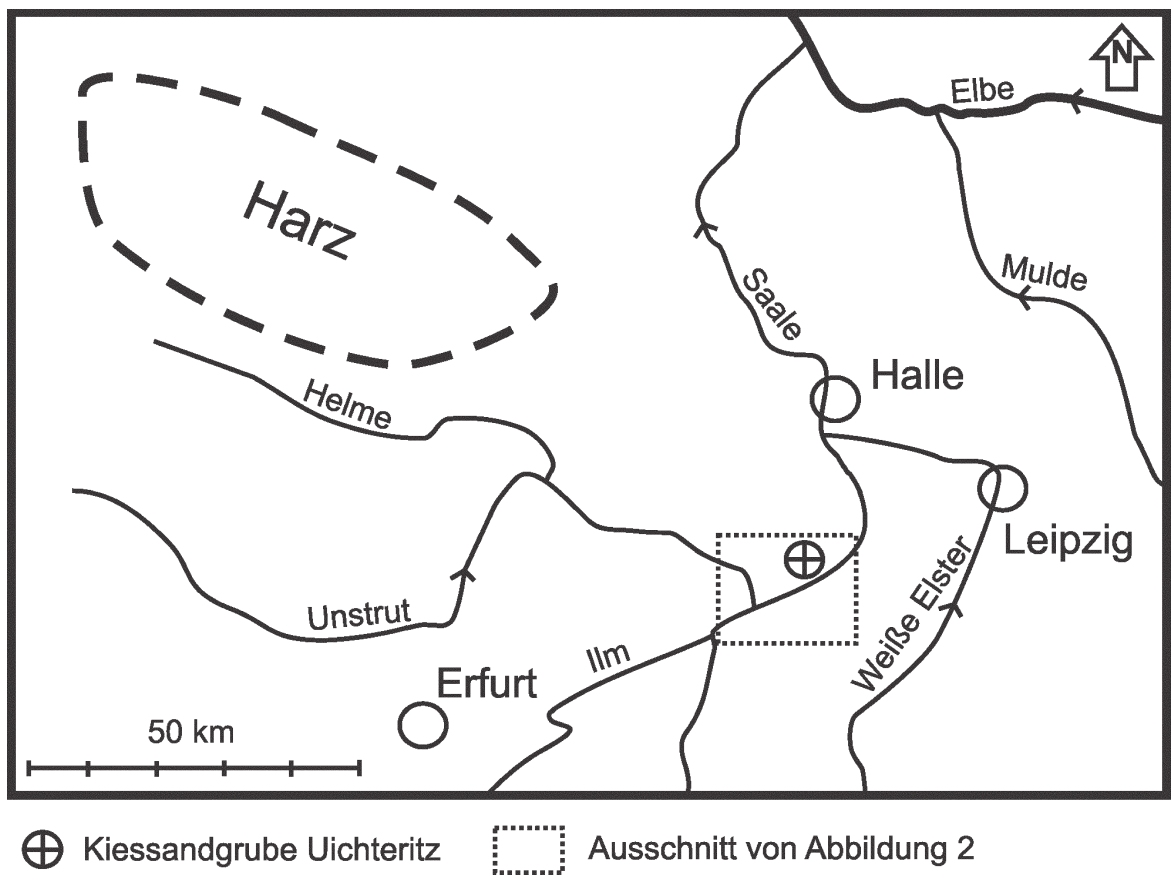

Abb. 1: Übersichtskarte mit Lage der Kiessandgrube Uichteritz im Saale-Unstrut-Gebiet in Mitteldeutschland.

Fig. 1: General map showing the gravel and sand pit Uichteritz in the Saale-Unstrut area, Central Germany. 
Inlandeises in den mitteldeutschen Raum. Diese Fragen erlangen durch zahlreiche Funde von Steinartefakten aus den Schottern des höheren Terrassenniveaus (Weber et al. 1996) besondere Brisanz, denn es geht letztlich auch um die Frage, wann der Mensch dieses Gebiet erstmals betreten hat. Über das Uichteritzer Artefaktinventar berichten Rudolph et al. in diesem Band.

Den Anlass für die hier vorgestellten Untersuchungen boten Hinweise von Prof. Dr. L. Eißmann, Leipzig, und A. Rudolph, Leipzig, auf neuere Mollusken- und Artefaktfunde in der Kiessandgrube der Firma H. Antons \& Sohn, Jülich, die sich ca. $500 \mathrm{~m}$ westlich der Ortslage Uichteritz auf einem Sporn zwischen dem Saa- letal und dem vom Röhlitzbach durchflossenen Markröhlitzer Tal befindet (Abb. 1 und 2).

Anlässlich einer gemeinsamen Befahrung am 26.01.2001 wurden die Probleme eingehend diskutiert und erste Dokumentationen und Beprobungen vorgenommen.

\section{Kenntnisstand mit besonderer Berücksichtigung der Schotterterrassen}

\subsection{Präquartär bis frühe Elster-Kaltzeit}

Der präquartäre Untergrund wird bei Uichteritz

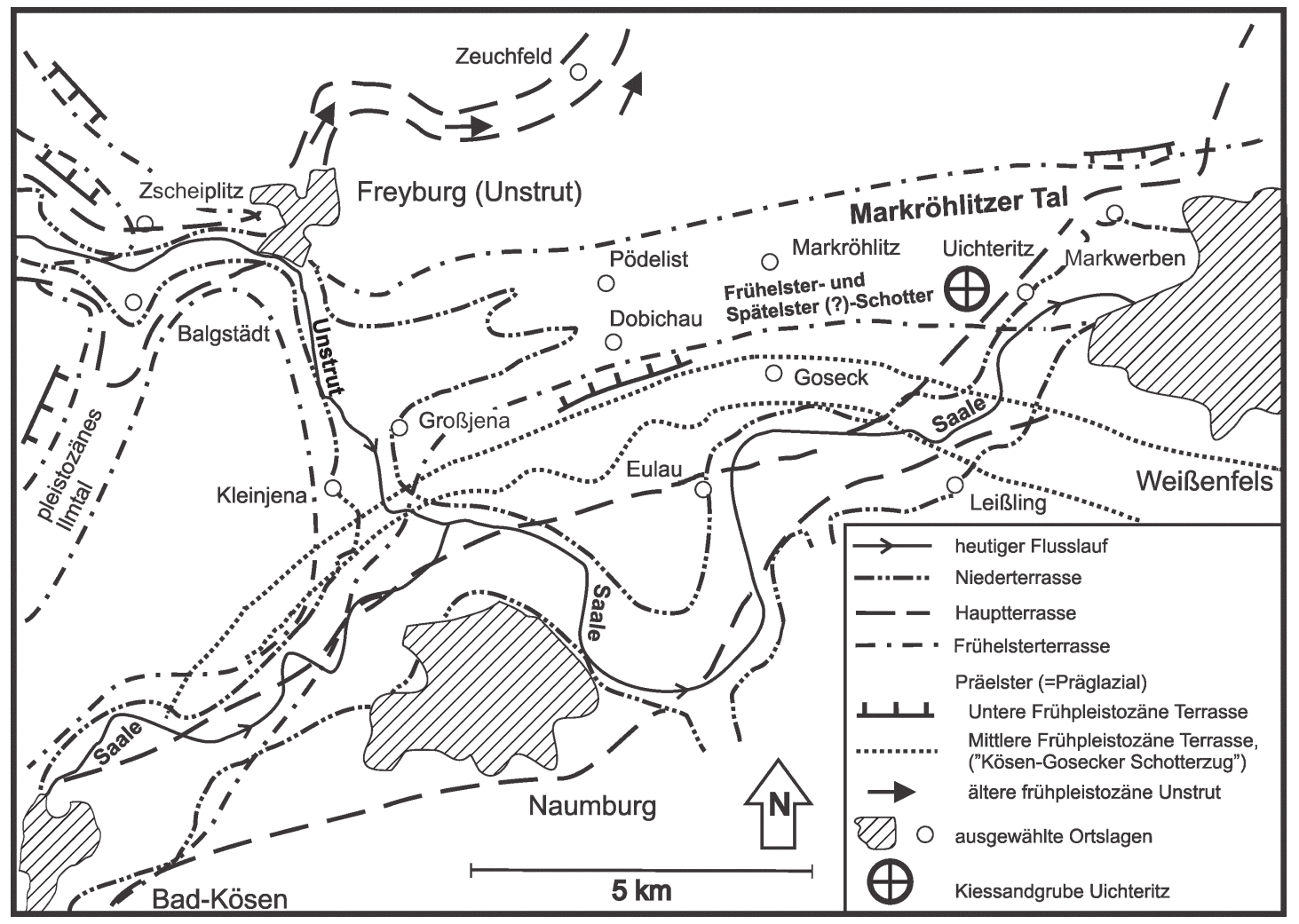

Abb. 2: Karte der pleistozänen Flussgeschichte von Saale und Unstrut im Umfeld von Uichteritz, z. T. vermutet (nach Eissmann 1975, SteinmülLer 1976, 1980, verändert) (Karte entspricht Ausschnitt in Abb. 1).

Fig. 2: Map of the Pleistocene history of the Saale and Unstrut rivers in the Uichteritz area, partly proposed (after Eissmann 1975, Steinmüller 1976, 1980, modified). The location of this area is marked in fig. 1. 
von flach nach NW einfallenden Sedimentiten des Tafeldeckgebirges am SE-Rand der Freyburger Mulde, der südöstlichen Teilstruktur der Querfurter Mulde bestimmt. Nach der Aufnahme von P. KARPE, Landesamt für Geologie und Bergwesen Sachsen-Anhalt, Halle, vom 14.09.1993, standen in der Kiessandgrube der Fa. H. Antons \& Sohn im Niveau der Grubensohle rotbraune bis violette feinschichtige Tonund Schluffsteine an. Sie dürften nach Bohrungen im Umfeld der Kiessandgrube, insbesondere im südlich angrenzenden Bewilligungsfeld Uichteritz/Lobitzsch, zur Solling-Folge des Mittleren Buntsandsteins gehören (FANTASNY 1996, Dr. K.-H. Radzinski, Halle, freundl. mündl. Mitt.). Zumindest im östlichen Teil des derzeitigen Grubenbereiches wird die Unterlage der quartären Ablagerungen von hellolivgrauen Mergelsteinen mit Fasergipseinlagerungen aus dem Salinarröt gebildet.

Die quartären Ablagerungen beginnen im Raum Weißenfels mit Saaleschottern ohne nordisches Material (sog. präglazialen Schottern), die als isolierte Vorkommen in verschiedenen Höhenlagen seit langem bekannt sind und unterschiedlich stratifiziert wurden. Zum ältesten und mit ca. 170-180 m NN am höchsten gelegenen Terrassenniveau gehören die Saalekiese bei Goseck („Kösen-Gosecker Schotterzug“ nach Wüst 1901a)(Abb. 2). Die ca. 70-80 m über der heutigen Saaleaue bei Uichteritz gelegenen Schotter wurden von Siegert \& WeisSERMEL (1911) zu ihrer „Zweiten Präglazialen Saaleterrasse" und von Eissmann (1975) zur „Mittleren Frühpleistozänen Terrasse“ gerechnet, STeINmüller (1976) hat sie helmekaltzeitlich eingeordnet.

In vereinzelten Schottervorkommen im Niveau von 140-150 m NN bei Markwerben (40-50 m über Aue) haben Siegert \& Weissermel (1911) Relikte ihrer „Dritten Präglazialen Terrasse“ gesehen. Sie verbanden diese Schotter mit einem Kiesvorkommen bei Großjena und gelangten damit zu der Überzeugung, dass die Saale be- reits damals durch das Markröhlitzer Tal geflossen ist. Eissmann (1975) hat diese Vorkommen gemeinsam mit in gleichem Niveau nachgewiesenen Schottern bei Markröhlitz der „Unteren Frühpleistozänen Terrasse" zugeordnet.

Während Siegert \& Weissermel (1911) und Eissmann (1975) in der Stratifizierung der alten Schotterreste im Wesentlichen konform gehen, vertrat Schulz (1962) die Auffassung, dass die Höhenunterschiede der beiden hochliegenden Terrassenniveaus durch eine Verwerfung oder Flexur verursacht wurden. Quartärtektonische Bewegungen sind jedoch im Untersuchungsgebiet weitgehend auszuschließen (EIssmanN 1964). Schulz verband die hochliegenden Schotter mit seiner „Unteren Präglazialen (=frühelsterzeitlichen) Terrasse" und nahm an, dass das Markröhlitzer Tal in präglazialer Zeit noch nicht als eigenständige Talung existierte, sondern Teil eines ca. $5 \mathrm{~km}$ breiten Saaletales war.

Während die chronostratigraphische Einordnung der älteren, höherliegenden präglazialen Terrassenrelikte noch nicht hinreichend geklärt ist, konnten bereits Siegert \& Weissermel (1911) die Verknüpfung ihrer am tiefsten gelegenen „Vierten Präglazialen Terrasse“ mit der ersten (elsterzeitlichen) Vergletscherung nachweisen. Allerdings waren im Markröhlitzer Tal damals noch keine frühelsterzeitlichen Schotter bekannt. Ruske \& WÜNsche (I964) beschrieben aus Bohrungen bei Pödelist feuersteinfreie Saale-Unstrut-Schotter im Niveau von ca. 125 m NN (25-30 m über Aue) unter mächtiger Elster-Grundmoräne. Sie belegen gemeinsam mit weiteren lokalen Schottervorkommen (STEINMÜLLER 1976), dass die frühelsterzeitliche Saale von Großjena aus durch das Markröhlitzer Tal geflossen ist. Insbesondere aufgrund geomorphologischer Indizien vertraten diese Auffassung bereits Naumann \& Picard (i 909), Siegert \& Weissermel (i9i i), Lehmann \& LehManN (I930) sowie Kugler (1961). Schließlich sei erwähnt, dass STEINMüller (1976) die 
tiefliegenden feuersteinfreien Schotter mit dem 140-150 m NN-Niveau zu Frühelsterschottern zusammengefasst hat.

In der frühen Elster-Kaltzeit ist die Ilm bei Zscheiplitz in die Unstrut gemündet (NaUMann \& Picard 1909). Die Saale nahm bei Freyburg die vereinigte Unstrut/Ilm auf (LeHMANN 1922) und floss durch das Markröhlitzer Tal nach Weißenfels (EIssmann i 964, Ruske \& WÜNSCHE 1964).

\subsection{Elster-Kaltzeit bis unterer periglaziärer Teil des Saale-Komplexes}

Während der Elster-Kaltzeit drang das skandinavische Inlandeis bis an den Rand der sächsischen und thüringischen Mittelgebirge vor. Das Untersuchungsgebiet wurde wahrscheinlich von zwei Eisvorstößen überfahren. $\mathrm{Zu}$ den Hinterlassenschaften zählen die westlich von Markröhlitz verbreitet auftretenden Grundmoränen und zahlreiche Vorkommen von Schmelzwasserbildungen (STEINMÜLleR 1976). Bei Pödelist sind zwei durch Bänderton und Schmelzwassersande getrennte Elster-Grundmoränen erbohrt worden, die zusammen fast 50 m mächtig werden (RUSKE \& WüNSCHE 1964). Die glaziäre Talverschüttung hatte zur Folge, dass sich die Flüsse nach dem Abschmelzen der Gletscher zum Teil neu orientieren mussten. Bereits im ausgehenden Elsterglazial ist eine starke fluviatile Dynamik mit wechselnder Erosion und Akkumulation anzunehmen.

Weissermel (i 908 ) hat zwischen Markröhlitz und Uichteritz in mehreren Kiessandgruben beiderseits des Röhlitzbaches eine höhere Terrasse der Saale kartiert. Die im Niveau von 130-140 m NN bzw. ca. 30-40 m über der rezenten Saaleaue angetroffenen Schotter waren bis $10 \mathrm{~m}$ mächtig und wurden von Geschiebemergel und Löss bzw. Schwemmlöss überlagert. Die Trennung der höheren Saaleterrasse von der
Hauptterrasse wurde in zwei Schnitten veranschaulicht, die Höhendifferenzen der Terrassenunterkanten von fast $20 \mathrm{~m}$ zeigen (WeIsSERMEL 1908, Siegert \& Weissermel i9ii: Tafel 2). Siegert \& Weissermel hielten beide Terrassen für erstinterglaziale Bildungen und nahmen an, dass die Saale im ersten Teil des „Großen Interglazials" (=Holstein-Warmzeit) das Markröhlitzer Tal benutzte.

Petrographisch soll sich die höhere Terrasse gegenüber der tieferen durch einen etwas höheren Anteil an nordischem Material und örtlich durch das Auftreten bis kopfgroßer nordischer Blöcke auszeichnen (Siegert \& WeIssermel I9I I). Molluskenschalen wurden bevorzugt in dünnen sandigen Schichten und nesterweise in grobem Schotter gefunden. Die von Siegert \& Weissermel (I9I I: I 50) aufgeführten Formen erlauben jedoch keine paläoökologischen Rückschlüsse.

Auch Schulz (1962) sah die „höhere mittelpleistozäne Terrasse" als holsteinwarmzeitlich an. Er ging von einer Erosionsphase zu Beginn der Warmzeit aus und nahm wie Siegert \& Weissermel (1911) an, dass die Saale in der ersten Hälfte des "Großen Interglazials" das Markröhlitzer Tal benutzte. Erst EIssmanN (1975) argumentierte für die Einstufung der Uichteritzer Schotter in die späte Elster-Kaltzeit (Kap. 1).

Die Holstein-Warmzeit ist im Saale-Unstrutgebiet durch wärmeliebende Molluskenfaunen mit zahlreichen exotischen Elementen sowie durch Funde von Waldnashorn und Waldelefant belegt (Siegert \& Weissermel 1911, Toepfer 1935, Mania 1973). Außerdem treten intensive Bodenbildungen in Erscheinung (Freyburger Bodenkomplex), deren stratigraphische Zuordnung innerhalb des Zeitraums HolsteinWarmzeit bis Dömnitz-Warmzeit jedoch strittig ist (Ruske \& WünsChe 1961, 1964 HaAse et al. 1970, Mania \& Altermann 1970, Ruske 1973).

Die Akkumulation der Hauptterrasse erfolgte 
mehrphasig und vertritt den langen, durch die Dömnitz/Wacken-Warmzeit und möglicherweise noch weitere Wärmeschwankungen gegliederten Zeitraum vom ausgehenden Holstein-Interglazial bis zum Vorstoß des Saale-Inlandeises. Die Hauptterrassen von Saale und Unstrut sind jedoch hauptsächlich kaltklimatisch akkumuliert worden, wie zahlreiche Frostmarken und Funde von kälteresistenten Großsäugern zeigen (EIssmann 1975). Die Saale-Hauptterrasse liegt bei Uichteritz im Niveau von 115-125 m NN bzw. 15-25 m über der Aue, also ca. $15 \mathrm{~m}$ tiefer als die höhere mittelpleistozäne Terrasse. WeIssermel (I908) hat sie an den Hängen beiderseits der Saale kartiert. Er hat auch den von Wüst (1901b) aus der Kiesgrube von Albert Ködel am nördlichen Ende von Uichteritz beschriebenen 2,5 m mächtigen Saalekies mit nordischen Geröllen der Hauptterrasse zugeordnet. Im östlichsten Teil der Grube war dicht über der Sohle ein wenige Zentimenter mächtiges graugrünes Tonbänkchen in den Kies eingeschaltet, das viele Molluskenschalen enthielt. Aus dem Ton oder wenig darüber wurden auch zwei Molaren von Elephas trogontherii PoHL. geborgen. Da WÜsт (1901b) die Mollusken aufgrund von Vergleichen mit thüringischen Vorkommen in das zweite Interglazial einstufte (=Eem-Warmzeit), gab der Fund der Molaren Anlass zu Vermutungen, ob E. trogontherii (Mammuthus trogontherii) bis in das letzte Interglazial existiert haben könnte oder ob mit Umlagerungen des Fundmaterials zu rechnen ist. Nach heutiger Kenntnis ist der Mollusken-Fundhorizont aber mit Sicherheit älter als die Eem-Warmzeit.

SäNGER (1928) erkannte den überwiegend kaltzeitlichen Charakter der Hauptterrasse in der Umgebung von Weißenfels. Den Schottern aus der Ködelschen Grube bei Uichteritz und der „im Tälchen südlich Storkau liegende(n) Stadelmannsche Grube" billigte SäNGER (1928: 21) jedoch aufgrund der Fossilfunde eine „Interglazialnatur" zu.
Für die Hauptterrassenzeit gilt als sicher, dass die Saale bereits wie heute die Ilm bei Großheringen aufgenommen hat und dann weiter über Naumburg nach Weißenfels geflossen ist (NAUManN \& Picard 1909). Die Unstrut nutzte ab Freyburg das Zeuchfelder Tal und erreichte die Saale erst im Raum Bad Dürrenberg - Merseburg (Schulz i962, Eissmann 1975).

\subsection{Glaziärer Teil des Saale-Komplexes (Drenthe-Stadium) bis Holozän}

Während des Drenthe-Stadiums des SaaleKomplexes stieß das Inlandeis in drei Phasen in die Leipziger Tieflandsbucht vor, doch nur der erste Vorstoß (Zeitzer Phase) hat den Raum Weißenfels erreicht und ist im Saaletal etwa bis Bad Kösen vorgedrungen (EIssmann 1975, Knoth 1995). Vor der Eisfront bildeten sich ausgedehnte Stauseen, in denen laminierte feinkörnige Sedimente, z. T. mit Jahresschichtung (Bänderton), akkumuliert wurden. Aus den abgeriegelten Flusstälern sind örtlich extrem mächtige Stauseeablagerungen bekannt (Baettenstaedt i934, Ruske 1961). Die Grundmoräne des Saale-Inlandeises ist nördlich des Markröhlitzer Tales weit verbreitet, weiter südlich sind vor allem glazifluviatile Sedimente überliefert (STEINMÜLler 1976).

Im jüngeren Drenthe-Stadium und im Warthe-Stadium war das Untersuchungsgebiet periglaziären Klimabedingungen ausgesetzt. Aus dieser Zeit stammen u. a. die Löss-/Schwemmlössakkumulationen, auf denen sich in der Eem-Warmzeit und der frühen Weichsel-Kaltzeit der Naumburger Bodenkomplex (RusKe \& WüNSCHE 1961, 1964) entwickelt hat. In der Weichsel-Kaltzeit ist das nordische Eis nur bis in das Gebiet südlich von Berlin vorgestoßen. Der Saale-Unstrut-Raum unterlag wiederum periglazialem Klima mit trockeneren und feuchteren Phasen. Auf den 
Hochflächen und in den Hanglagen wurden Löss, Schwemmlöss und Fließerden sedimentiert, die in der Weichsel-Kaltzeit und im Holozän partiell durch Bodenbildungen überprägt wurden. Die Flüsse haben ihre Niederterrasse aufgeschüttet. Die Niederterrasse der Saale liegt bei Uichteritz ca. $20 \mathrm{~m}$ tiefer als die Hauptterrasse und wird von holozänen Auesedimenten bedeckt. Das rezente Aueniveau befindet sich hier in ca. $98 \mathrm{~m} \mathrm{NN}$.

\section{Lithologie in der Kiessandgrube Uichteritz}

Die Aufschlussdokumentation in der Kiessandgrube der Fa. H. Antons \& Sohn bei Uichteritz erstreckte sich über den Zeitraum von Januar 2001 bis Juni 2003, mit einzelnen Befahrungen bis zum Juni 2005. Dabei wurde angestrebt, Lithologie und Lagerungsverhältnisse der quartären Schichtenfolge im Grubengelände detailgetreu zu erfassen. Die Stoßaufnahmen erfolgten überwiegend im Bereich des derzeit aktiven Kiesabbaus im SE der Grube und repräsentieren verschiedene Abbaustände (Abb. 3: Profile 2-8). Ausgangspunkt der Untersuchungen waren Molluskenfunde in den ca. $200 \mathrm{~m}$ voneinander entfernt liegenden, lithologisch sehr unterschiedlich aufgebauten Profilen 1 und 2.

Für die Verbindung der beiden Profile stand lediglich Profil 9 an der südlichen Grubenausfahrt zur Verfügung, da die Böschung in diesem Bereich durchgängig stark überrollt war.

Die über $10 \mathrm{~m}$ mächtige quartäre Schichtenfolge umfasst Flussablagerungen, Verschwemmungsablagerungen, Schmelzwasserbildungen, Geschiebemergel, Fließerde, Löss und Schwemmlöss. Im Mittelpunkt der Betrachtung stehen die fluviatilen Kiese, die sich durch aushaltende feinkörnige Zwischenlagen, durch differenzierte Verwitterung und mit Einschränkungen auch durch die Geröllzusammensetzung gliedern lassen. Es konnten drei horizontal bis schwach nach Norden geneigte übereinander

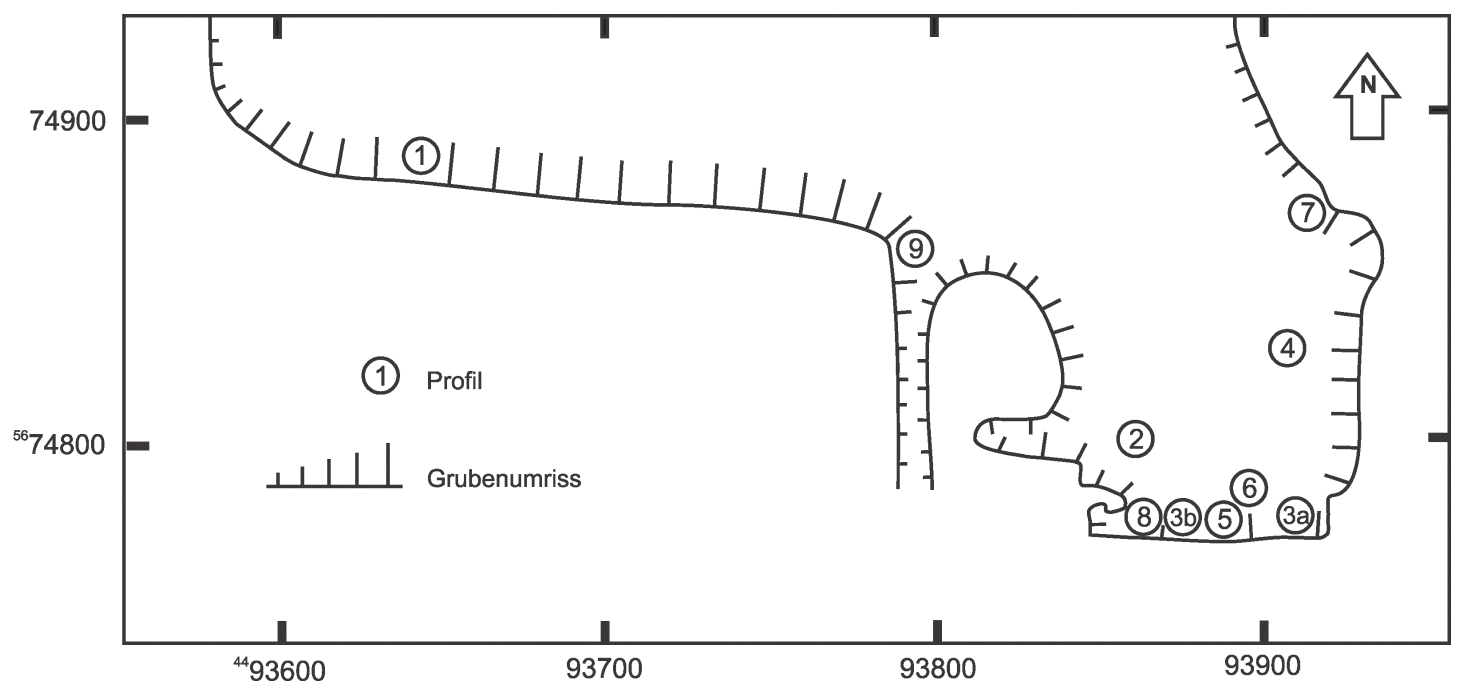

Abb.3: Lagekarte der untersuchten Profile 1 bis 9 im Südteil der Kiessandgrube Uichteritz (Gauss-KrügerKoordinaten).

Fig. 3: Location map of investigated profiles number 1 to 9 in the southern part of the gravel and sand pit Uichteritz (German grid coordinates). 


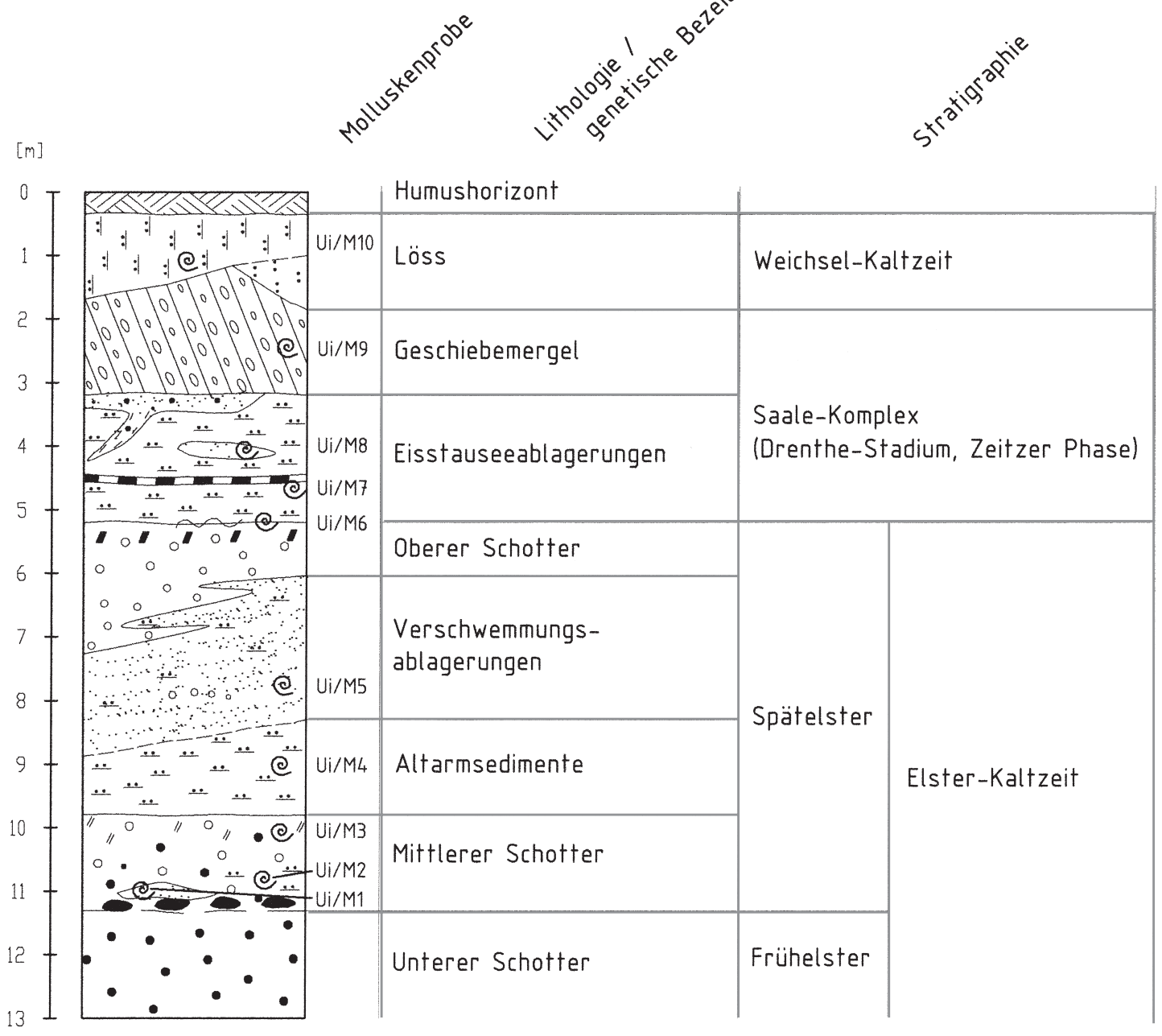

Abb. 4: Normalprofil des Quartärs von Uichteritz mit Molluskenfundhorizonten (Legende in Abb. 5b).

Fig. 4: General profile of the Quaternary sequence of Uichteritz including horizons of molluscs found (legend in fig. 5b). 
liegende Schotterkörper ausgehalten werden. Die Synopse aller Aufschlussaufnahmen ergab das in Abb. 4 dargestellte Normalprofil.

\subsection{Profile 2 bis 8 im Südostteil der Grube}

Unterer Schotter: Die Sedimentfolge beginnt mit ca. $2 \mathrm{~m}$ mächtigem, überwiegend horizontalgeschichtetem, Steine führendem sandigem Mittel- und Grobkies, teilweise mit Imbrikationsgefüge (Dachziegellagerung). Schrägschichtung tritt bevorzugt in sandigeren Partien auf. In Profil 2 schneiden sich die groben Kiese in fluviatile mittelsandige Feinsande ein, die eine feinkörnige Fazies des Unteren Schotters darstellen. Der Kies ist örtlich durch eine schwach ausgeprägte Steinsohle aus Sandstein, Quarz und Kalkstein untergliedert (Abb. 5a: Profil 2). In Profil 5 haben sekundäre Kalzitausscheidungen dicht über der Buntsandstein-Oberfläche zur Zementation der Gerölle geführt. Wesensmerkmal und entscheidendes Kriterium für die Abgrenzung gegen die überlagernden Schotter ist das Fehlen nordischer Gerölle (Kristallin, Flint). Der meist hellgraue Flussschotter wirkt im Allgemeinen frisch und weist nur in den Profilen 1 und 5 Verwitterungsmerkmale auf (Kalkreduzierung, Verbraunung). Vereinzelte rote bis violette Toneinlagerungen sind auf die Aufarbeitung von Röt-Material zurückzuführen.

Mittlerer Schotter: Im basalen Bereich des Mittleren Schotters tritt eine mehr oder weniger deutlich ausgeprägte $S \mathrm{t}$ e i $\mathrm{n} \mathrm{s}$ o h le mit einzelnen Blöcken bis ca. $40 \mathrm{~cm}$ Kantenlänge in Erscheinung. Örtlich ist der ganze untere Teil des Schotterkörpers stark mit Steinen und Blöcken angereichert (Abb. 5a: Profil 8). Das Grobmaterial enthält nordisches Kristallin und Feuerstein, aber auch lokale Komponenten (Quarz, plattigen Sandstein und Kalkstein). Die Steinsohle kann jedoch nicht generell als
Basis des Mittleren Schotters angesehen werden, da vereinzelt noch bis etwa $50 \mathrm{~cm}$ darunter nordische Gerölle gefunden wurden.

Direkt über der Steinsohle oder durch geringmächtigen Kies von ihr getrennt folgen lückenhaft verbreitet $20-40 \mathrm{~cm}$ sandiger, schwach toniger Schluff mit Fein- und Mittelkiesen. Die grüngraue fließerdeähnliche $U \mathrm{n} \mathrm{t}$ e $\mathrm{r}$ e $\mathrm{Schluffschichtist} \mathrm{in} \mathrm{der} \mathrm{Regel} \mathrm{in} \mathrm{lang-}$ gestreckte Linsen aufgelöst und geht örtlich in graubraunen schluffigen Feinsand über (Profil 5). Die Schluffe und Feinsande stellen die tiefsten Mollusken-Fundhorizonte im Normalprofil dar (Abb. 4). In den Kiesen wurden nur vereinzelt Molluskenreste und nicht näher bestimmbare Knochenfragmente gefunden.

Über der Unteren Schluffschicht lagern ca. 2 m mächtige grobe fluviatile Kiese, in denen Lagen mit bis zu $20 \mathrm{~cm}$ großen Steinen vorkommen. Dadurch erscheint der Mittlere Schotter oft gröber als der Untere und der Obere, und die meist horizontale Schichtung ist oft nur undeutlich ausgebildet (Abb. 6). Lagenweise ist Imbrikationsgefüge erkennbar. Auffällig sind besonders die eckigen und kantengerundeten plattigen Sandsteine, die nur einen kurzen Transportweg zurückgelegt haben können und dem Fluss als Hangschutt zugeführt wurden (vgl. STEINMÜLLER 1982). In den steinigen Kiesen kommen stellenweise feinsandige Schlufflinsen vor, die meist kryoturbat deformiert sind.

Der Mittlere Schotter ist in der Regel verbraunt, doch variiert die Verwitterungsintensität erheblich. In Profil 4 ist lediglich eine Verbraunung, verbunden mit Kalkreduzierung in der Matrix zu beobachten, an anderen Stellen ist auch ein geringmächtiger, nicht aushaltender Bt-Horizont entwickelt (Profile 5 und 6). Die Kalkstein-Gerölle sind hier restlos ausgemerzt (Tab. 1a: Probe Ui/S6). Wo der Schotter direkt von feinkörnigen glaziären Bildungen überlagert wird, treten generell stärkere Eisenoxidationen auf, die ein fossiles Grundwasserniveau anzeigen (Abb. 7). In Profil 2 ist die Kalkstein- 


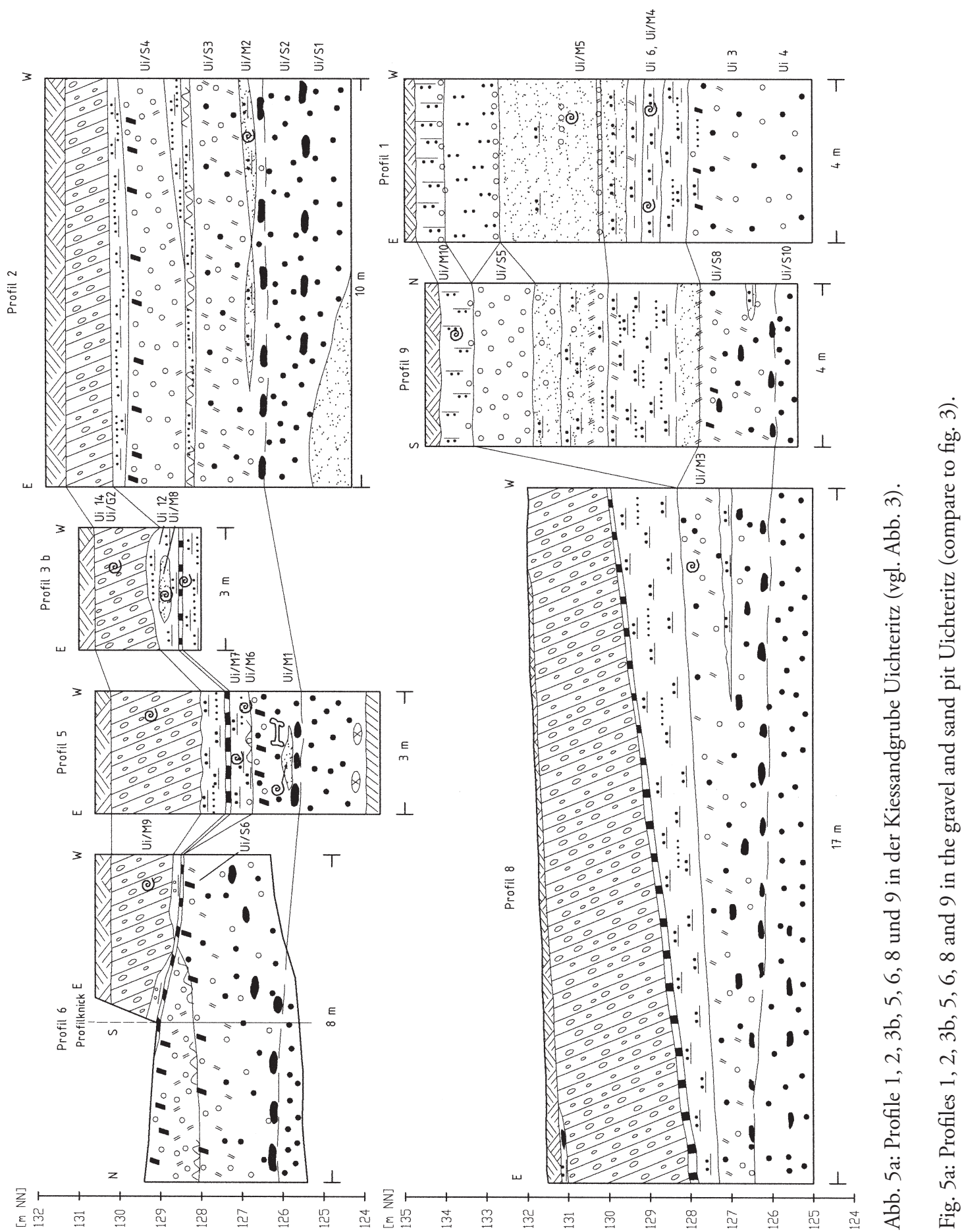



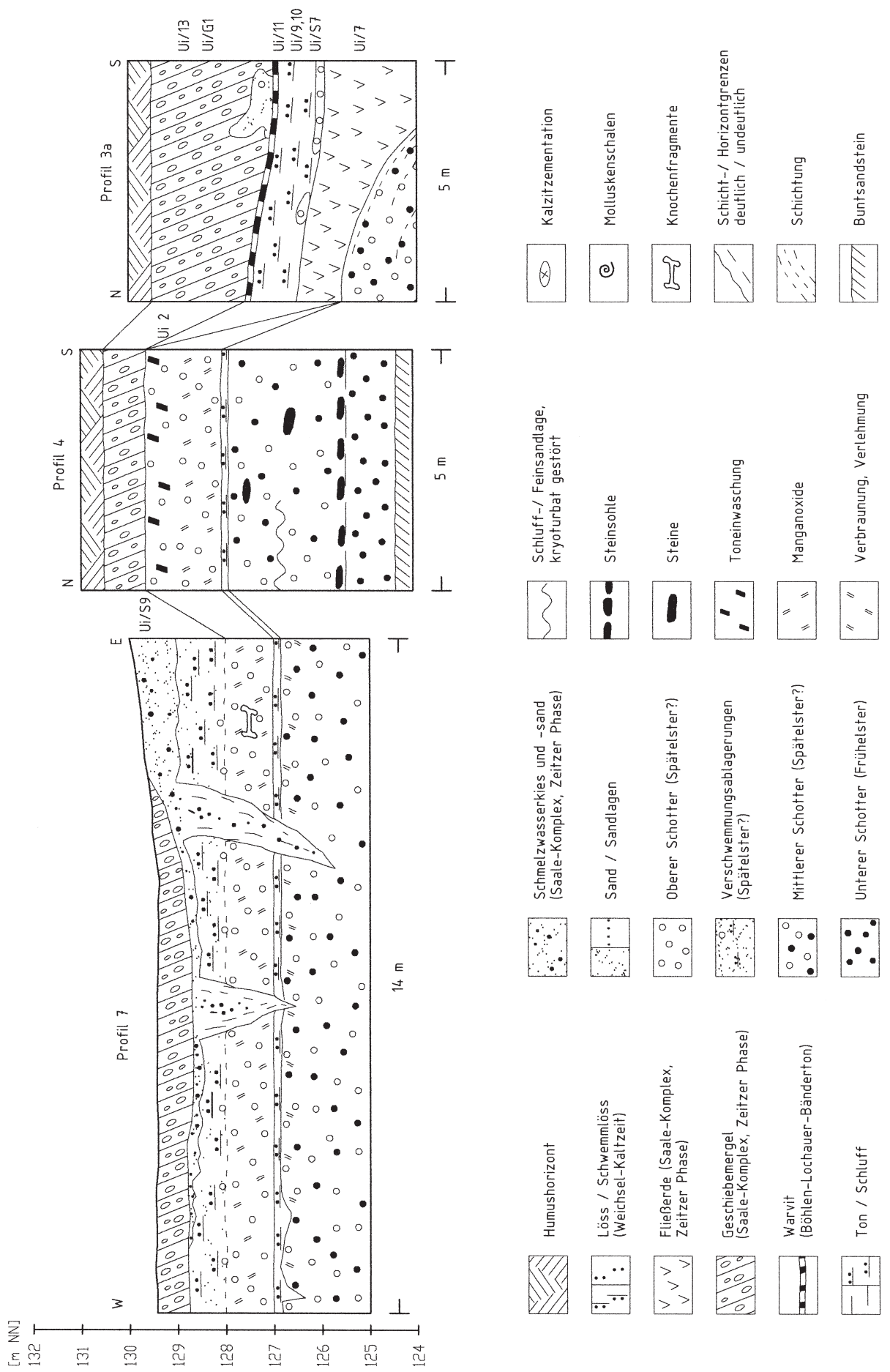


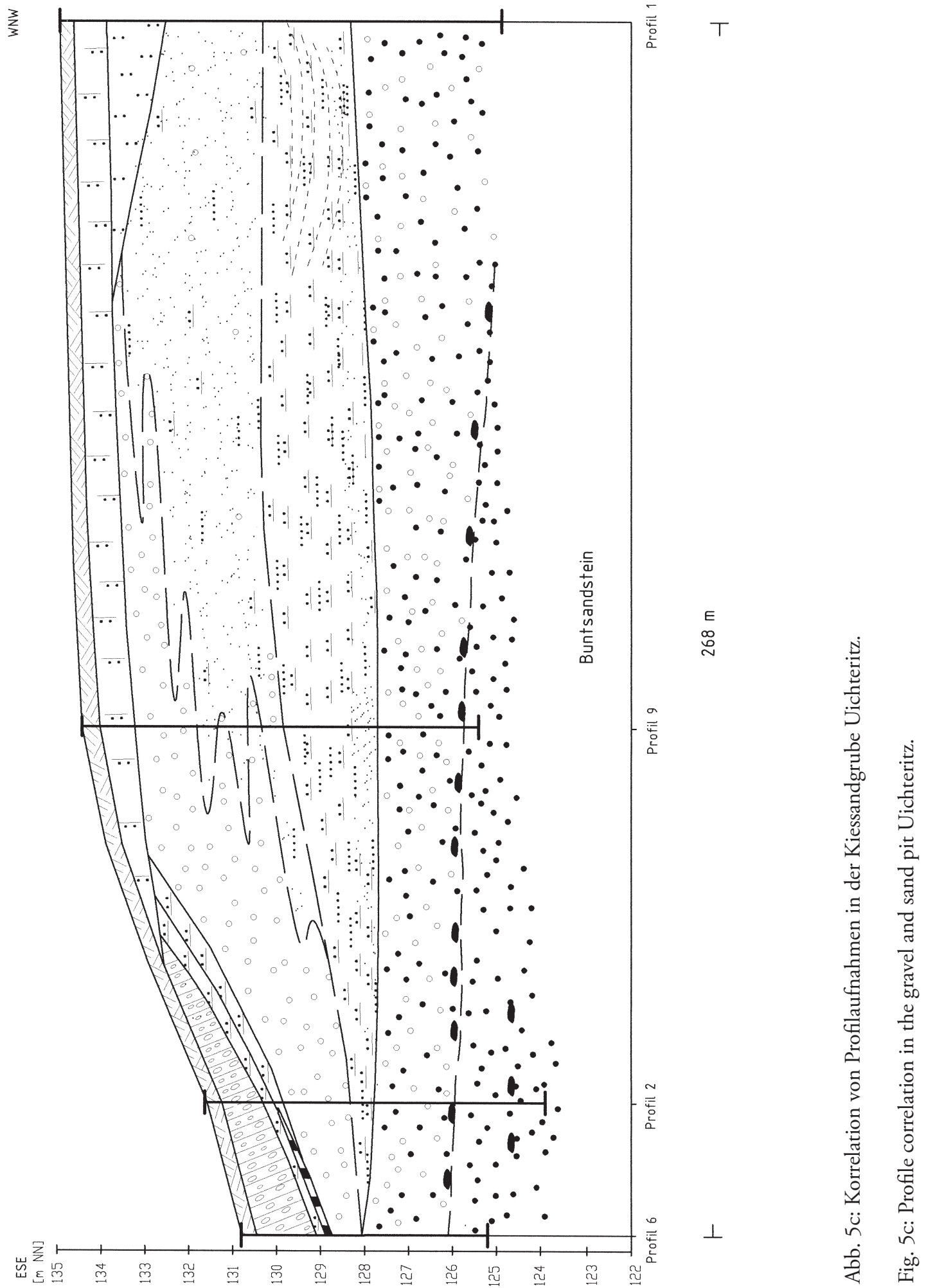






Abb. 6: Oberer Schotter mit Bt-Horizont und Manganoxid-Horizont über kryoturbater Schluffschicht (hell, ca. $50 \mathrm{~cm}$ über der $2 \mathrm{~m}$-Messlatte), Mittlerem Schotter und Hangendbereich des Unteren Schotters (untere $20 \mathrm{~cm}$ ); Aufnahme entspricht etwa dem Nordteil von Profil 6 in Abb. 5a, Kiessandgrube Uichteritz, 23.04.2002, Foto: Wansa.

Fig. 6: The Upper Gravel Unit with argillaceous horizon and Mn-oxide horizon above cryoturbatic silt (light, ca. $50 \mathrm{~cm}$ above the 2 meter scale marker), the Middle Gravel Unit and the upper part of the Lower Gravel Unit. The picture corresponds to the northern part of profile 6 in fig. 5a. Gravel and sand pit Uichteritz. 23 April, 2002, photo: Wansa.

Komponente der Gerölle stark reduziert (Tab. 1a: Probe Ui/S3) und viele Kiese haben Eisenoxid-Beläge. Die feinkörnigen Schichten darüber sind sogar kalkfrei. Wie im Unteren Schotter treten gelegentlich Toneinlagerungen aus aufgearbeitetem Röt-Material auf.

Obere Schluffschicht: Zwischen Mittlerem und Oberem Schotter lagern verbreitet bis $50 \mathrm{~cm}$ mächtige Altwassersedimente (Abb. $5 \mathrm{a}$ und b). Die meist kryoturbat deformierten, sandig-tonigen Schluffe mit Kiesen sind durch helle grünlich-graue Reduktionsfarben leicht erkennbar. Das Material ist teils kalkig, teils kalkfrei und trägt, ähnlich wie die Untere Schluffschicht, Fließerdecharakter. In Profil 2 entwickelt sich aus dem kryoturbaten Schluff eine bis $50 \mathrm{~cm}$ mächtige Wechsellagerung aus kalkfreiem Sand und Schluff (an der Basis tonigem Schluff). Örtlich werden die Schluffe durch Kies mit schluffigen Einlagerungen oder einen Kryoturbationshorizont vertreten (Profile 5 und 6). In Profil 7 ragt eine kleine keilförmige Struktur (Eiskeil?) in die unterlagernden Schotter.

Oberer Schotter: Der bis $2 \mathrm{~m}$ mächtige Obere 
Tab. 1a: Geröllzählungen aus der Kiessandgrube Uichteritz (Fraktion 6,3 - 20 mm, Korn-\%).

US - Unterer Schotter, MS - Mittlerer Schotter, OS(u) - Oberer Schotter (umgelagert), gf - Glazifluviatil.

Tab. 1a: Analyses of fluvial gravels from the gravel and sand pit Uichteritz (grain size range $6.3-20 \mathrm{~mm}$, grain \%).

US - Lower Gravel Unit, MS - Middle Gravel Unit, OS (u) - Upper Gravel Unit (resorted), gf - glaciofluvial sediments.

\begin{tabular}{|l|c|c|c|c|c|c|c|c|c|c|}
\hline Probennummer & Ui/S1 & Ui/S2 & Ui/S3 & Ui/S4 & Ui/S5 & Ui/S6 & Ui/S7 & Ui/S8 & Ui/S9 & Ui/S10 \\
\hline Zuordnung & US & US & MS & OS & OS & MS & Osu & MS & gf & US \\
\hline Geröllanzahl & 482 & 403 & 466 & 402 & 471 & 399 & 435 & 535 & 309 & 517 \\
\hline Kristallin & 0 & 0 & 0,9 & 2,7 & 3,0 & 1,3 & 3,0 & 1,5 & 11,7 & 0,4 \\
\hline Porphyr & 13,7 & 8,2 & 7,7 & 10,2 & 11,3 & 8,0 & 7,6 & 8,2 & 10,7 & 8,1 \\
\hline Kalkstein & 40,9 & 61,3 & 4,1 & 34,6 & 33,5 & 0 & 34,0 & 0 & 21,7 & 47,8 \\
\hline Feuerstein & 0 & 0 & 0,4 & 1,2 & 1,3 & 0,5 & 2,5 & 0,7 & 8,7 & 0 \\
\hline Quarz & 14,3 & 6,0 & 27,7 & 24,4 & 24,2 & 34,6 & 20,7 & 38,5 & 22,0 & 12,2 \\
\hline Ton-/Schluffstein & 0,2 & 0 & 0 & 0 & 0,4 & 0,5 & 0,2 & 0,2 & 0 & 0 \\
\hline Sandstein & 2,1 & 1,7 & 1,7 & 3,0 & 3,4 & 4,0 & 3,0 & 2,8 & 2,3 & 2,1 \\
\hline Quarzit & 12,4 & 8,7 & 13,5 & 7,5 & 5,3 & 10,0 & 8,3 & 15,7 & 14,9 & 10,1 \\
\hline Grauwacke & 5,0 & 3,7 & 13,3 & 9,0 & 2,5 & 12,3 & 5,3 & 8,8 & 1,3 & 3,3 \\
\hline Kieselschiefer & 2,7 & 3,0 & 3,0 & 1,2 & 2,1 & 2,0 & 3,7 & 3,0 & 1,6 & 3,7 \\
\hline Tonschiefer/Phyllit & 8,3 & 7,2 & 26,6 & 6,0 & 12,7 & 26,8 & 11,5 & 20,4 & 4,9 & 12,0 \\
\hline Sonstige & 0,4 & 0,2 & 1,1 & 0,2 & 0,2 & 0 & 0,2 & 0,2 & 0,3 & 0,4 \\
\hline Summe & 100,0 & 100,0 & 100,0 & 100,0 & 99,9 & 100,0 & 100,0 & 100,0 & 100,1 & 100,1 \\
\hline Neubildungen & 0 & 0,5 & 0,6 & 0,7 & 0,4 & 0 & 1,4 & 0,2 & 4,2 & 0 \\
\hline
\end{tabular}

Tab. 1b: Geröllzählungen ohne Kalkstein.

Tab. 1b: Gravel analyses without limestone.

\begin{tabular}{|l|c|c|c|c|c|c|c|c|c|c|}
\hline Probennummer & Ui/S1 & Ui/S2 & Ui/S3 & Ui/S4 & Ui/S5 & Ui/S6 & Ui/S7 & Ui/S8 & Ui/S9 & Ui/S10 \\
\hline Zuordnung & US & US & MS & OS & OS & MS & Osu & MS & gf & US \\
\hline Geröllanzahl & 285 & 156 & 447 & 263 & 313 & 399 & 287 & 535 & 242 & 270 \\
\hline Kristallin & 0 & 0 & 0,9 & 4,2 & 4,5 & 1,3 & 4,5 & 1,5 & 14,9 & 0,7 \\
\hline Porphyr & 23,2 & 21,2 & 8,1 & 15,6 & 16,9 & 8,0 & 11,5 & 8,2 & 13,6 & 15,6 \\
\hline Feuerstein & 0 & 0 & 0,4 & 1,9 & 1,9 & 0,5 & 3,8 & 0,7 & 11,2 & 0 \\
\hline Quarz & 24,2 & 15,4 & 28,9 & 37,3 & 36,4 & 34,6 & 31,4 & 38,5 & 28,1 & 23,3 \\
\hline Ton-/Schluffstein & 0,4 & 0 & 0 & 0 & 0,6 & 0,5 & 0,3 & 0,2 & 0 & 0 \\
\hline Sandstein & 3,5 & 4,5 & 1,8 & 4,6 & 5,1 & 4,0 & 4,5 & 2,8 & 2,9 & 4,1 \\
\hline Quarzit & 21,1 & 22,4 & 14,1 & 11,4 & 8,0 & 10,0 & 12,5 & 15,7 & 19,0 & 19,3 \\
\hline Grauwacke & 8,4 & 9,6 & 13,9 & 13,7 & 3,8 & 12,3 & 8,0 & 8,8 & 1,7 & 6,3 \\
\hline Kieselschiefer & 4,6 & 7,7 & 3,1 & 1,9 & 3,2 & 2,0 & 5,6 & 3,0 & 2,1 & 7,0 \\
\hline Tonschiefer/Phyllit & 14,0 & 18,6 & 27,7 & 9,1 & 19,2 & 26,8 & 17,4 & 20,4 & 6,2 & 23,0 \\
\hline Sonstige & 0,7 & 0,6 & 1,1 & 0,4 & 0,3 & 0 & 0,3 & 0,2 & 0,4 & 0,7 \\
\hline Summe & 100,1 & 100,0 & 100,0 & 100,1 & 99,9 & 100,0 & 99,8 & 100,0 & 100,1 & 100,0 \\
\hline
\end{tabular}




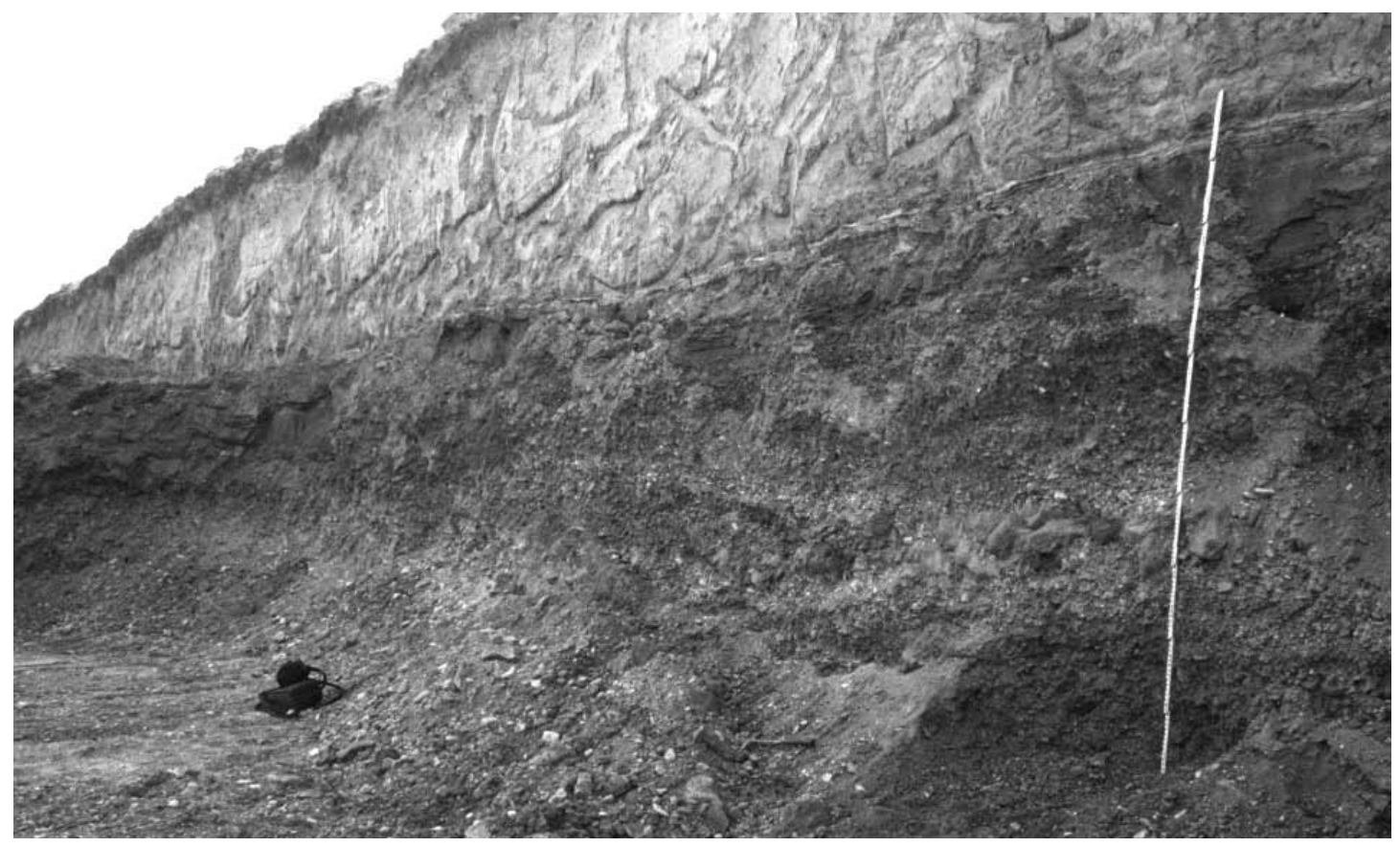

Abb. 7: Grundmoräne über Bänderton (am oberen Ende der 3 m-Messlatte) und verbrauntem Mittleren Schotter; Aufnahme entspricht etwa Profil 5 in Abb. 5a, Kiessandgrube Uichteritz, 11.03.2002, Foto: Wansa.

Fig. 7: Till above warved clay (at the upper end of the scale) and Middle Gravel Unit. The picture corresponds to profile 5 in fig. 5a. Gravel and sand pit Uichteritz. 11 March, 2002, photo: Wansa.

Schotter besteht wie der Mittlere vorwiegend aus grobem Kies, enthält aber weniger Steine. Auch dieser fluviatile Schotterkörper ist im Allgemeinen horizontalgeschichtet (teilweise mit Imbrikationslagerung), Schrägschichtungspartien treten nur in sandigen Partien auf. In Profil 7 (Abb. 5b) beginnt der Schotter als kiesiger Sand und weist tendenziell eine inverse Gradierung auf. In Profil 6 (Abb. 5a, c) wird der obere Teil des Oberen Schotters von Bänderton und Geschiebemergel gekappt, im benachbarten Profil 5 fehlt er völlig. Hier reichte die Erosion bis in den Mittleren Schotter.

Der Obere Schotter ist durch starke Verwitterung überprägt (Abb. 6: Profil 6). Die obersten $40-70 \mathrm{~cm}$ sind entkalkt, weisen Tonhäutchen auf (Abb. 8) und stellen einen Bt-Horizont dar. In Profil 4 war an Wurzelbahnen gebundene sekundäre Kalkbildung zu beobachten. Im unteren Bereich des Schotters sind die Kalksteine erhalten geblieben und die meist mit Manganoxid-Dendriten oder Eisenoxid überzogenen Gerölle sind z. T. durch Kalzitzement verkrustet. Dieser fossile Grundwasserhorizont trennt den entkalkten Abschnitt des Oberen Schotters von dem entkalkten oder kalkreduzierten Abschnitt des Mittleren Schotters bzw. der feinkörnigen Zwischenlage.

Auffällig ist, dass stärkere Manganoxidabsätze bevorzugt im Niveau zwischen der kryoturbaten Schluffschicht und dem hangenden Bt-Horizont in Erscheinung treten, also im unteren Teil des Oberen Schotters.

Fließerde: In der SE-Ecke der Kiessandgrube Uichteritz werden die fluviatilen Kiese von ei- 


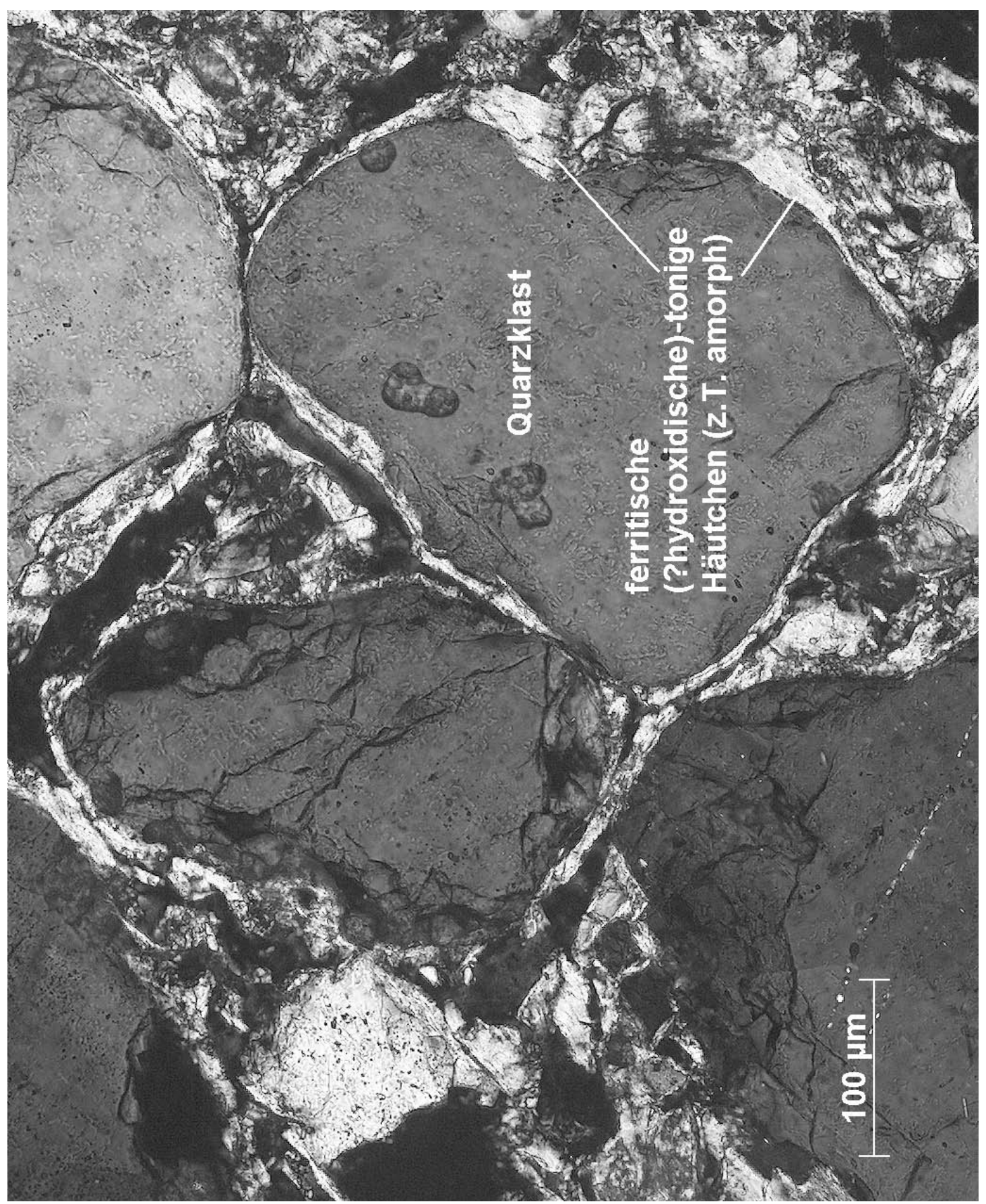

Abb. 8: Sekundäre Tonminerale im Oberen Schotter aus Profil 4, Probe Ui 2 (Dünnschliff: C. Büchner, LAGB Sachsen-Anhalt, Halle).

Fig. 8: Secondary clay minerals within the Upper Gravel Unit in profile 4, sample Ui 2 (thin section: C. Büchner, LAGB Sachsen-Anhalt, Halle). 


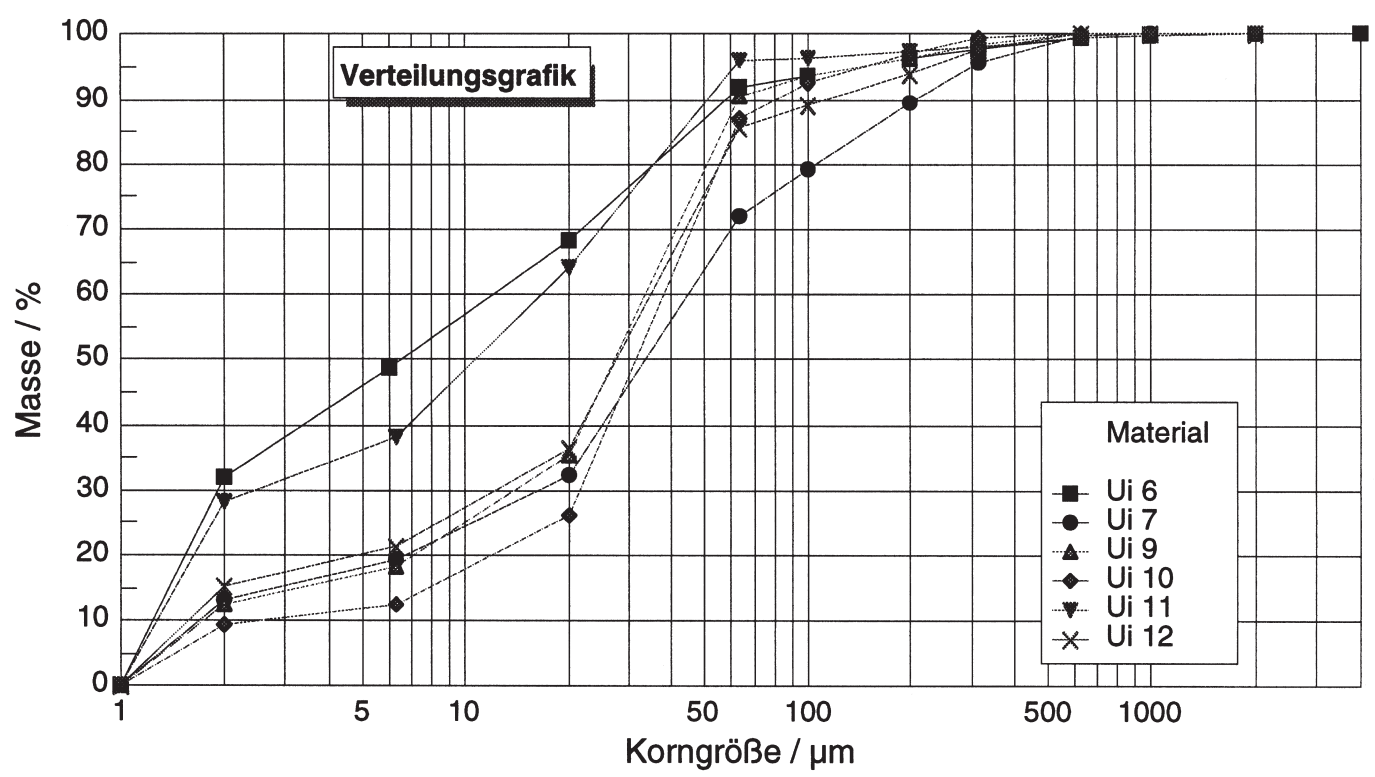

Abb. 9: Kornverteilungen von Eisstauseebildungen (Ui 9-12), Altwasserablagerungen (Ui 6) und Fließerde (Ui 7) aus der Kiessandgrube Uichteritz.

Fig. 9: Grain size distribution of glaciolimnic sediments (Ui 9-12), oxbow sediments (Ui 6) and flow material (Ui 7) in the gravel and sand pit Uichteritz.

ner Diskordanzfläche abgeschnitten (Abb. 5b: Profil 3a), deren Genese nicht eindeutig geklärt werden konnte. Möglicherweise handelt es sich um die Flanke einer durch Subrosion von Rötsalz verursachten Hohlform, wofür auch die zur Senke hin abbiegende Schichtung der benachbarten bzw. abgeschnittenen Kiese spricht. Die Hohlform hat an der Aufschlusswand eine Ausdehnung von ca. $10 \mathrm{~m}$. Sie ist zum großen Teil durch hellbraunen, stark kalkigen, tonigsandigen Schluff mit gehäuft auftretenden Kalk-Pseudomyzelen und Kalkkonkretionen gefüllt. Das unsortierte, schwach geschichtete Material stellt eine Fließerde dar (Probe Ui 7) und erreicht über $2 \mathrm{~m}$ Mächtigkeit (Abb. 5b: Profil 3a). Im oberen Teil sind zunehmend Mittel- und Grobkieslagen und -linsen mit max. $40 \mathrm{~cm}$ Mächtigkeit enthalten. Diese durch Kalkzement verbackenen Kiese stammen vermutlich aus dem Oberen Schotter (Tab. 1: Probe Ui/S7).
Eisstauseebildungen: Über der Fließerde bzw. über dem Oberen oder Mittleren Schotter lagert feinschichtiger, braungelber, unten z. T. auch hellbrauner B e c k e n s c h l u ff (Abb. 5a: Profile 2, 5 und 8, Abb. 5b: Profil 3a und 7). Seine Mächtigkeit beträgt meist nur einige Dezimeter bis $1 \mathrm{~m}$, im W von Profil 8 fast $2 \mathrm{~m}$. Die Proben Ui 9 und Ui 10 haben ähnliche Kornverteilungen mit einem starken Maximum in der Grobschlufffraktion (55,2 bzw. 60,9 \%, Abb. 9). Der Feinsandanteil resultiert vor allem aus vielen nicht aushaltenden, bis $1 \mathrm{~cm}$ mächtigen, welligen Lagen und Linsen. Der Kalkgehalt liegt bei 6-8 \%. An der Basis wurden vereinzelt Fein- und Mittelkiese beobachtet, örtlich auch eine stärkere Aufarbeitung des liegenden Schotters. Aus diesem vermischten Material wurden in Profil 5 (Abb. 5a) Molluskenschalen geborgen, ebenso aus dem hangenden, hier blaugrau gefärbten Schluff (Kap. 6.3).

Die Sedimentation erfolgte wohl in einem 
flachen Becken vor dem Eisrand. Nach der Kornverteilung und der Farbe ist damit zu rechnen, dass der glazilimnische Schluff z. T. aus der Umlagerung von Löss hervorgegangen ist. Möglicherweise ist auch eine äolische Komponente enthalten. In Profil 7, das vermutlich näher am Beckenrand liegt, bauen sich die äquivalenten Sedimente aus einer markanten Wechsellagerung von schwach tonigem Schluff und Feinsand mit vereinzelten Fein- und Mittelkiesen auf.

Der Beckenschluff wird im Hangenden konkordant, aber meist mit deutlicher Grenze durch einen typischen $\mathrm{W}$ a $\mathrm{r}$ v i t abgelöst. Die Kornsummenkurve der Mischprobe Ui 11 dieser bis $23 \mathrm{~cm}$ mächtigen, kalkigen Wechsellagerung aus hellem graugelbem Schluff und dunklem braungrauem schluffigem Ton zeigt einen bimodalen Verlauf mit Maxima in der Ton- und der Mittel-/Grobschlufffraktion (Abb. 9). Die Lagenmächtigkeiten betragen im Mittel 1-1,5 cm (helle Lagen) bzw. 0,5 cm (dunkle Lagen) und nehmen nach oben zu, was den Warvit als Vorstoßbänderton ausweist. Die gröberen Lagen sind intern geschichtet. Der Bänderton besteht aus max. 9 deutlich ausgebildeten Warven, von denen die oberen stellenweise Deformationen aufweisen.

Am Rand des Eisstaussees dünnt der Bänderton aus und wird zunehmend von Beckenschluff vertreten. Oft sind zwischen Bänderton und überlagerndem Geschiebemergel noch bis $1 \mathrm{~m}$ kalkhaltiger Beckenschluff in deformierter Lagerung eingeschaltet, der dem Geschiebemergel farblich sehr ähnlich ist (Abb. 5a: Profile 3b und 5, Abb. 9: Probe Ui 12, Abb. 10). Dieser Beckenschluff enthält lokal hellgrünlich-graue und blaugraue Sand-Einlagerungen, die sich durch gehäuft auftretende Molluskenschalen auszeichnen (Kap. 6.3).

Schmelzwassersand: Nur in Profil 7 (Abb. 5b) tritt zwischen Beckenschluff und Geschiebemergel ca. $1 \mathrm{~m}$ mächtiger, schräggeschichteter, kiesiger Sand in Erscheinung. Die Geröllzusammensetzung unterscheidet sich durch den hohen Gehalt an Nordischem Kristallin und Feuerstein wesentlich von den übrigen Geröllproben, so dass die Interpretation als glazifluviatiles Vorschüttsediment gesichert ist (Tab. 1: Probe Ui/S9).

Profil 7 zeigt zwei Eiskeilpseudomorphosen. Die größere wird etwa $3 \mathrm{~m}$ tief und hat eine Schulterbreite von ca. 0,5 m. Die Keilstrukturen setzen in den glazifluviatilen Kiessanden an, durchschlagen den liegenden Beckenschluff und ragen bis in die fluviatilen Schotter. Es sind die einzigen in Uichteritz beobachteten Eiskeile und auch die einzigen Beweise für wiederholte starke Temperaturabsenkungen während der Schotterakkumulation.

Grundmoräne: Das Vorkommen der bis $3 \mathrm{~m}$ mächtigen Grundmoräne ist wie das der liegenden Stauseebildungen an eine flache erosive Eintiefung im Schotter gebunden. Ihre Ausdehnung ist deshalb auf den E- und SE-Bereich der Kiessandgrube begrenzt, bereits an der südlichen Ausfahrt (Abb. 5a, c: Profil 9) ist sie nicht mehr vorhanden.

Die Grundmoräne besteht aus einem braunen, stark klüftigen Geschiebemergel. Nach der Kornverteilung handelt es sich um sandigen, schwach tonigen Schluff mit vielen kleinen Geschieben (Fein- und Mittelkiese). Die Kornverteilung entspricht der der oben beschriebenen Fließerde (Abb. 9: Probe Ui 7) und unterscheidet sich von der des liegenden lössähnlichen Beckenschluffs nur durch ein geringer ausgeprägtes Grobschluff-Maximum. Wo Geschiebemergel direkt über Beckenschluff lagert, ist die Grenze meist undeutlich ausgebildet und nicht überall eindeutig fassbar, denn beide Sedimente haben auch sehr ähnliche Farben und der Geschiebemergel führt nur vereinzelt größere Geschiebe. An der Basis ist örtlich Liegendmaterial (Sand, Kies, Beckenschluff, Bänderton) glazitektonisch deformiert und in die Grundmoräne 
eingeschert worden (Abb. 10).

Der Kalkgehalt der Matrix beträgt ca. $10 \%$. Örtlich ist der Geschiebemergel von Kalkpseudomyzelen durchsetzt und enthält zahlreiche Kalkkonkretionen. Die oberen $30-50 \mathrm{~cm}$ sind humifiziert (Ap-Horizont) und werden im Liegenden von einer Steinsohle begrenzt.

Der Geschiebemergel führt in der Matrix, örtlich auch in Form von Lagen und Linsen viel Lokalmaterial, u. a. Beckenschluff. Im oberen Moränenteil sind mitunter langgestreckte Sandlinsen oder eckige Sandstein-Blöcke zu beobachten. Auf dem kurzen Transportweg im Gletscher wurde die Sedimentfracht offenbar kaum mechanisch beansprucht. Dies belegen auch die in der gesamten Grundmoräne verteilten Funde von gut erhaltenen Molluskenschalen. LAVRušın (1978: 172) erklärt die
Erhaltung von leicht zerstörbaren FaunenÜberresten in den Grundmoränen damit, „daß die Zertrümmerungs- und Zerreibungsprozesse nicht überall gleichartig wirksam waren. ... Die gute Erhaltung organischer Reste kann man lediglich bei relativ kurzem Transportweg beobachten. ... Dies wird durch Beobachtungen in Grönland bestätigt, wo im mächtigen moränenhaltigen Eis quartäre Meeresmollusken bei teilweise sehr guter Erhaltung sowie völlig unbeschädigte Blätter der Zwergbirke usw. gefunden wurden."

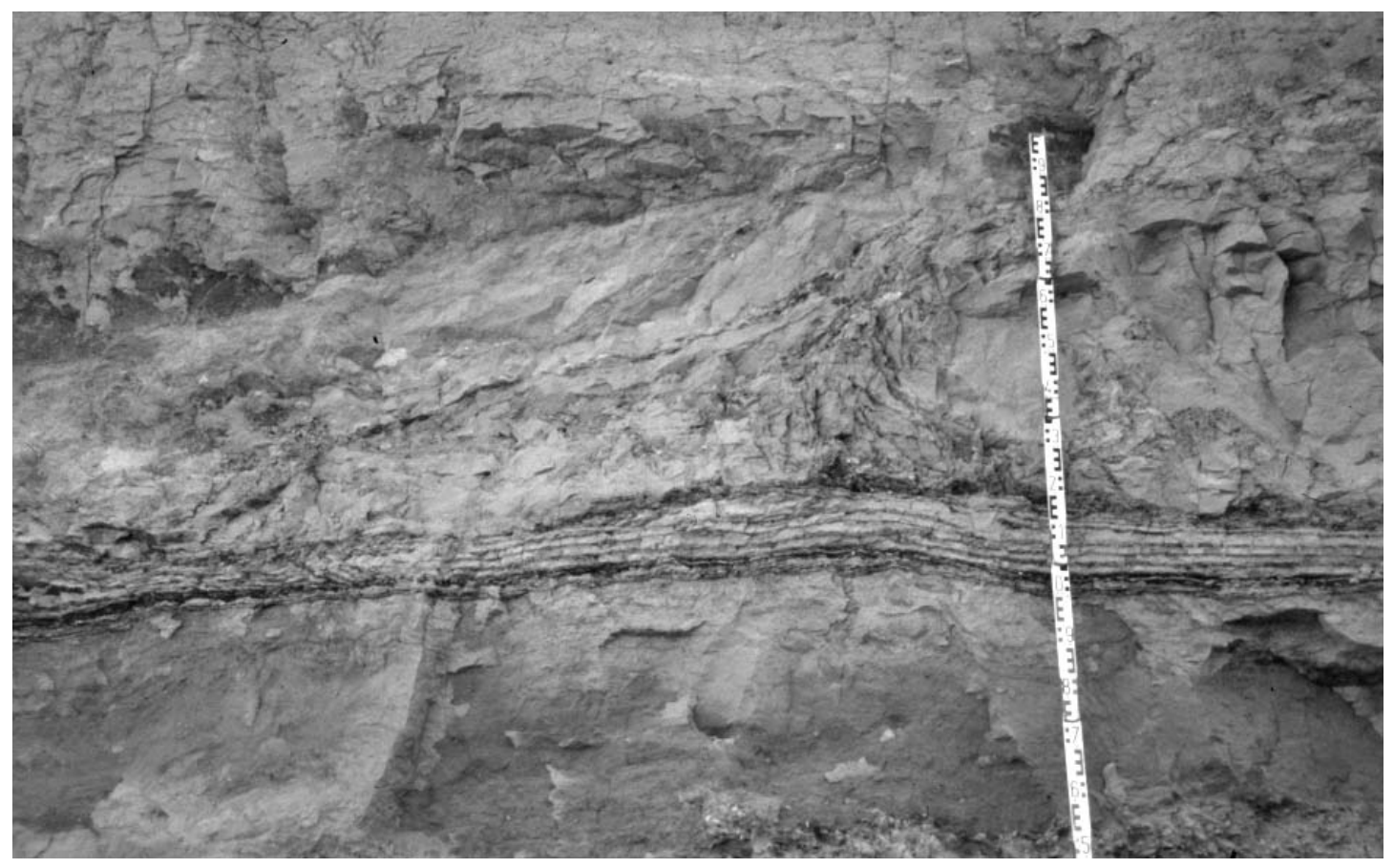

Abb. 10: Bänderton (oberer Teil glazitektonisch deformiert) und Beckenschluff an der Basis der Saale-Grundmoräne, Kiessandgrube Uichteritz, 22.03.2003, Foto: Wansa.

Fig 10: Warved clay upper part glaciotectonically deformed) and silt at the base of the Saalian till. Gravel and sand pit Uichteritz. 22 March, 2003, photo: Wansa. 


\subsection{Profil 9 an der südlichen Ausfahrt}

Die Aufnahme von Profil 9 an der südlichen Grubenausfahrt (Abb. 5a, c) erfolgte mit dem Ziel, eine Korrelation der Profile 2-8 mit Profil $1 \mathrm{zu}$ ermöglichen. Profil 9 beginnt mit dem hellgrauen Unteren Schotter, der nur etwa $30 \mathrm{~cm}$ über die Grubensohle ragt. Die im südöstlichen Grubengelände verbreitete Steinsohle bildet hier die markante Grenze zum fast $2 \mathrm{~m}$ mächtigen, groben kiesig-steinigen Mittleren Schotter. In dessen unterem Teil fällt eine Linse aus ockerfarbenem und olivgrauem schluffigem Feinsand auf. Der Schotter ist durchgehend verbraunt und im oberen Abschnitt entkalkt. Ein dünner Manganoxid-Horizont grenzt den Kies gegen kalkfreien hellgraugelbem Sand ab, der zu einer überwiegend feinkörnigen kalkarmen Wechsellagerung von sandigen Schluffen und schluffigen Sanden überleitet. Bei diesen 2,3 m mächtigen Sanden und Schluffen handelt sich um Altwassersedimente, die mit der Oberen Schluffschicht im Südosten der Grube korrelieren. Sie werden von fast $2 \mathrm{~m}$ schwach kalkigem, hellgraugelbem kiesigem Sand überlagert, der sich im unteren Teil durch Manganoxid-Absätze hervorhebt und feinsandig-tonige Schlufflagen enthält. Dieser Profilabschnitt bildet den Verzahnungsbereich zwischen Oberem Schotter und Verschwemmungsablagerungen (Abb. 5c). Im Hangenden folgt der ca. 1,5 m mächtige Obere Schotter, der hier feinkörniger ausgebildet ist als in den in Kap. 3.1 beschriebenen Profilen, so dass seine Liegendgrenze nicht exakt ermittelt werden kann. Er besteht aus stark kalkigem, hellgelbgrauem, stark sandigem Kies. $1 \mathrm{~m}$ graugelber, oben humifizierter Löss schließt das Profil ab. Er enthält vereinzelt Molluskenschalen und an der Basis eine Gerölllage.

\subsection{Profil 1 im Südwestteil der Grube}

Das Profil 1 befindet sich in einem auflässigen Bereich im SW der Kiessandgrube (Abb. 3 und 5a, c). Die ca. $10 \mathrm{~m}$ mächtige Schichtenfolge beginnt im Liegenden mit $3 \mathrm{~m}$ entkalkten, rostfarbenen, oben rötlich-braunen Kiesen, die ganz wenig nordisches Material führen (Probe Ui 3) und dem Mittleren Schotter zuzuordnen sind. An der Basis sind bis $10 \mathrm{~cm}$ große plattige Kalksteine enthalten (Probe Ui 4), die aus einer Bankzone des Unteren Muschelkalkes der näheren Umgebung stammen dürften. Die oberen $50 \mathrm{~cm}$ des Schotters sind mit sandigen Schlufflagen durchsetzt und als Bt-Horizont ausgebildet. Im Hangenden folgen Altarmsedimente, die mit einer $75 \mathrm{~cm}$ mächtigen Wechsellagerung aus Schluff und Sandlagen (und -schlieren) beginnen. Sie ist kalkfrei und zeichnet sich durch violette und rötlich-braune Farbtöne aus. Mit deutlicher, oft „zerkneteter" Grenze lagern darüber $15-30 \mathrm{~cm}$ graublauer bis grünlich-grauer, kalkiger, stark toniger Schluff (Abb. 9: Probe Ui 6), der einen markanten Mollusken-Fundhorizont bildet und kleine Kalkkonkretionen enthält. Die Altwassersedimente enden mit $30 \mathrm{~cm}$ dunklem laminiertem Ton und Schluff. Sie werden von fast $3 \mathrm{~m}$ mächtigen Verschwemmungssedimenten bedeckt, die sich im unteren Teil aus hellbraunem schluffigem Sand mit Schluffbändern aufbauen und im oberen Teil aus kalkigem, schwach schluffigem, schwach mittelsandigem Feinsand mit Schluff-, untergeordnet auch Kieslagen. Dazwischen fällt eine durch Manganoxid schwarz gefärbte $15 \mathrm{~cm}$ mächtige Feinkies-Schicht auf. Die Verschwemmungsablagerungen sind horizontalgeschichtet und führen ganz vereinzelt Reste von Molluskenschalen. Über einem dünnen Kiesband folgt im Hangenden 1,4 m mächtiger hellbrauner Schwemmlöss mit Feinsandlagen. Den Profilabschluss bildet $1,2 \mathrm{~m}$ graugelber äolischer Löss (obere $40 \mathrm{~cm}$ Ap-Horizont, braungrau), der durch eine $10-15 \mathrm{~cm}$ mächtige Lage mit 
angereicherten Mittelkiesen von dem unterlagernden Schwemmlöss getrennt ist.

\section{Profilkorrelation und}

\section{Lagerungsverhältnisse}

Die in der Kiessandgrube Uichteritz aufgenommenen Profile sind nicht einheitlich aufgebaut, lassen sich aber aufgrund lithologischer Parallelen gut miteinander verbinden. An der in Abbildung 5c 10fach überhöht wiedergegebenen Südböschung verläuft die Grenze zwischen Unterem und Mittlerem Schotter in der Regel niveaubeständig im Bereich der Steinsohle oder bis ca. 0,5 m darunter. Zwischen dem Mittlerem Schotter und dem Löss bzw. Schwemmlöss treten mit nach Westen zunehmender Mächtigkeit feinkörnige Bildungen auf. Ihr unterer, schluffig-toniger Teil ist bei Profil 1 an eine flache, ca. 50-80 m breite Rinne gebunden und kann mit feinkörnigen Sedimenten in gleichem Niveau (Obere Schluffschicht) in den Profilen 2, 4, 7 und 9 korreliert werden. Sie stellen typische Ablagerungen in Altwasserbereichen dar. Der obere, sandige Teil wurde vermutlich überwiegend durch lateralen Eintrag schwemmfächerartig akkumuliert. Möglicherweise handelt es sich um umgelagerte Schmelzwassersedimente, die sich im Randbereich des Oberen Schotters mit diesem verzahnen. An der Basis markiert eine Kieslage die Erosion der Altwassersedimente.

Insgesamt weisen die Schotterkörper eine flach nach $\mathrm{N}$ geneigte Lagerung auf, die mit der vermuteten paläogeographischen Position an der südlichen Talflanke korrespondiert. Die angrenzenden Hochlagen wurden wahrscheinlich von elsterglaziären Sedimenten gebildet. Lagerungsstörungen aufgrund der Subrosion von Rötsalinar sind nicht belegt, können aber kleinräumig vermutet werden (Kap. 3.1).

Die Flussablagerungen werden durch jüngere Sedimente abgeschnitten, im Westen durch mächtigen Schwemmlöss und Löss, im Osten durch Fließerde, Eisstauseebildungen und eine Grundmoräne.

\section{Stratigraphie}

Die stratigraphische Einordnung der quartären Bildungen von Uichteritz erfolgt auf der Basis der Aufschlussdokumentationen sowie von Geröll- und Geschiebeanalysen und berücksichtigt den bisherigen Kenntnisstand (Kap. 2).

Bereits die Kartierer der Königlich Preußischen Geologischen Landesanstalt nutzten die Geröllzusammensetzung der Schotterterrassen für Aussagen zum Einzugsgebiet der Flüsse und zur fluviatilen Dynamik. Während sie sich in der Regel auf halbquantitative Einschätzungen beschränkten und die Aussagekraft von Kieszählungen in Frage stellten (Siegert \& Weissermel 1911), ist in der Mitte des vorigen Jahrhunderts eine Vielzahl von Kieszählungen durchgeführt und statistisch ausgewertet worden. Danach führen die Saaleschotter bei Weißenfels neben den Hauptkomponenten Quarz, Muschelkalk und Schiefergebirgsmaterial (Quarzit, Grauwacke, Tonschiefer/Phyllit, Kieselschiefer) auch höhere Anteile an Porphyr aus dem Thüringer Wald, die von Ilm und Unstrut (über den Zufluss des Gera-Systems) eingetragen werden (Schulz 1962, Eissmann 1964, 1975). Die Kalkstein-Komponente weist vor allem infolge von Verwitterung stark schwankende Werte auf und hat deshalb für vergleichende Betrachtungen nur eingeschränkte Relevanz.

\subsection{Präquartär bis frühe Elster-Kaltzeit}

Die quartäre Schichtenfolge beginnt mit dem Unteren Schotter, der im Aufschluss etwa im Niveau von 124-126 m NN anzutreffen ist. 
Die Geröllzusammensetzung des Schotterkörpers (Tab. 1) zeigt eine starke Dominanz von Muschelkalk sowie von Grundgebirgsmaterial aus dem Thüringischen Schiefergebirge und dem Harz. Reichlich vertreten sind auch Porphyr, vor allem aus dem Thüringer Wald (blaßviolett, einsprenglingsarm, z. T. ignimbritisch), und Quarz. Probe Ui/S10 enthält ganz wenig Gneis, der vom Kyffhäuser stammen könnte. Auch weiter oberhalb ist Kyffhäuser-Kristallin in Unstrutschottern nur spärlich vertreten (SteINmüller 1998). Nordisches Kristallin und Feuerstein fehlen, so dass der Schotter älter als die erste Elster-Vergletscherung ist. Nach der Höhenlage und der Geröllzusammensetzung handelt es sich um die Frühelsterterrasse der mit Ilm und Unstrut vereinigten Saale (vgl. EIsSMANN I964, I975, RUSKE \& WÜNSCHE 1964).

\subsection{Elster-Kaltzeit bis Holstein-Warmzeit}

Die Steinsohle mit reichlich nordischem Material im basalen Bereich des Mittleren Schotters stellt das Erosionsrelikt elsterglaziärer Ablagerungen dar und die nordische Komponente im Geröllbestand des Mittleren Schotters (125$128 \mathrm{~m} \mathrm{NN}$ ) belegt, dass dieser frühestens nach der ersten Elster-Vergletscherung abgelagert wurde. Offensichtlich ging der Akkumulation des Mittleren Schotters eine kräftige glazifluviatile und/oder fluviatile Erosionsphase voraus, die zur Ausräumung der elsterglaziären Sedimente geführt hat und bis in das Niveau der Frühelsterterrasse reichte. Alle Zählproben des Mittleren Schotters sind durch Kalkreduzierung bzw. -ausmerzung gekennzeichnet (Tab. 1a: Proben Ui/S3, Ui/S6 und Ui/S8), so dass für Vergleiche der Geröllzusammensetzungen Tab. 1b (ohne Kalkstein) herangezogen werden sollte. Für die Abgrenzung des Mittleren Schotters gegen den Unteren sind neben dem Auftreten nordischer Gerölle auch der geringere Por- phyr- und der höhere Quarz-Gehalt hilfreich. Da die Saale ihre Porphyr-Gerölle teils über das Gera-System und die Unstrut, teils über die Ilm bezieht, ließe sich die Verringerung auf die partielle Neuformierung der Flussläufe nach der elsterkaltzeitlichen Talverschüttung zurückführen (vgl. Kap. 2). Die Saale nutzte wie vor der Elster-Vergletscherung das Markröhlitzer Tal, die Unstrut war aber vielleicht bereits von ihr abgeschnitten, so dass die Porphyrkomponente durch den Ilm-Eintrag zu erklären wäre. Für zuverlässige Aussagen zur Flussgeschichte ist die Anzahl der vorliegenden Geröllzählungen aber zu gering.

Die heterogene Verwitterung des Mittleren Schotters wurde nicht allein durch einen fossilen Grundwasserstand verursacht, sondern trägt auch eine klimatische Komponente, d. h. sie bezeugt übereinstimmend mit den malakologischen Befunden eine wärmere Phase während der Schotterakkumulation.

Die Abgrenzung gegen den Oberen Schotter (128-133,5 m NN) ergibt sich aus der lithologischen Abfolge, dem Verwitterungsprofil und mit Einschränkungen auch durch die Geröllverteilung. Aufgrund verstärkter Aufarbeitung elsterglaziärer Sedimente ist ein etwas höherer Anteil an nordischem Material zu verzeichnen, und der etwas erhöhte Porphyrgehalt resultiert aus der stärkeren Zufuhr von Ilm-Material. Am Rande sei darauf hingewiesen, dass der Vergleich zwischen den Geröllzusammensetzungen der Uichteritzer Schotter und der SaaleHauptterrasse (EIsSMAnN 1975, STEINMÜLLER 1976) keine Bestätigung für den seit SIEgERT \& WeISSERMEL (1911) wiederholt beschriebenen größeren nordischen Geröllanteil in den höher gelegenen Schottern liefert. Wir halten sie deshalb für rein fluviatile Bildungen.

Die Altwasserbildungen, die schwache Diskordanz zwischen Oberem und Mittlerem Schotter und die Verzahnung mit Verschwemmungsablagerungen an der Talflanke geben Auskunft über die Flussdynamik. Sie ist offenbar durch 
lateral wechselnde Akkumulations- und Erosionsbereiche mit veränderlichen Fließrinnen und die Bildung von Stillwasserbereichen gekennzeichnet.

Mittlerer und Oberer Schotter entsprechen der "höheren interglazialen Terrasse der Saale" nach Siegert \& Weissermel (1911) bzw. der „höheren mittelpleistozänen Terrasse" von Schulz (1962). Die Kiessandgrube der Fa. Antons \& Sohn ist somit der erste Aufschluss, in dem die Frühelsterterrasse und die höhere mittelpleistozäne Terrasse in Superposition beobachtet wurden.

Allein aus dem Uichteritzer Aufschluss kann jedoch nicht mit Gewissheit entschieden werden, ob Mittlerer und Oberer Schotter intraelsterkaltzeitlich oder in der späten Elster-Kaltzeit akkumuliert wurden. Eine Konnektierung mit den von Ruske \& WÜNsche (1964) im Niveau von ca. $140 \mathrm{~m} \mathrm{NN}$ bei Pödelist zwischen zwei Elster-Grundmoränen beschriebenen Sanden mit einzelnen Kieslagen ist unwahrscheinlich. Da sich keinerlei Hinweise auf eine ElstereisÜberfahrung finden und in der Umgebung weder grobe Flussschotter noch Verwitterungsbildungen in die Zeit zwischen den Elster-Vergletscherungen datiert worden sind, halten wir eine spätelsterkaltzeitliche Entstehung für plausibeler. Schließlich kann auch ein frühsaalezeitliches Alter nicht gänzlich ausgeschlossen werden. Dagegen sprechen allerdings sowohl das gegenüber der Hauptterrasse um 10-15 m höhere Niveau als auch die Verwitterungsbildungen. Gestützt wird die spätelsterzeitliche $\mathrm{Zu}$ ordnung auch von paläontologischen Indizien, durch das Fehlen der Flussbewohner Theodoxus serratiliniformis GEYER 1914 oder Corbicula sp. (C. fluminalis auct. non O. F. MüLler 1774), welche wahrscheinlich für Schotterbildungen des Holsteins (Th.serratiliniformis ) und einer Frühsaale-Wärmeschwankung (Corbicula sp.) Leitcharakter besitzen und im mitteldeutschen Raum weit verbreitet sind. Die genaue stratigraphische Positionierung dieser Vorkommen wird allerdings bis heute kontrovers diskutiert (LeHmann 1922, Eissmann 1994, Knoth 1995, Meijer \& Preece 2000, Mania 1973, Mania \& Mar 2001 u. a.).

Nach den Molluskenbefunden (Kap. 6) fand die Schotterakkumulation unter interstadialen Klimabedingungen statt, die vermutlich auch die differenzierte Verwitterung des Mittleren Schotters verursacht haben.

Belege für wärmere Klimaabschnitte im Spätelster sind aus dem Raum Helmstedt bekannt (URBAN et al. 1988, 1991), konnten aber im Saale-Elbe-Gebiet bisher nicht beigebracht werden.

\subsection{Saale-Komplex bis Weichsel-Kaltzeit}

Zwischen der Akkumulation des Oberen Schotters und der Fließerde bzw. der glazilimnischen Vorschüttbildungen ist mit einer größeren Schichtlücke zu rechnen, die den Zeitraum von der Holstein-Warmzeit bis zum Vorstoß des Saale-Inlandeises nach Mitteldeutschland umfasst.

Die im südöstlichen Aufschlussbereich anstehende Grundmoräne muss wegen der Unterlagerung durch Flussschotter mit nordischem Material jünger sein als die erste Elster-Vergletscherung. Eine Zuordnung zum 2. ElsterEisvorstoß ist wegen der Verwitterungsprofile auf den Schottern eher unwahrscheinlich. Der obere Geschiebemergel in der Bohrung Pödelist (2. Elster-Grundmoräne) weist zudem eine signifikant abweichende Geschiebezusammensetzung mit höheren Kristallin- und geringeren Porphyr-Anteilen auf (vgl. Ruske \& WÜNSCHE 1964). Auch der Habitus und die Geschiebezusammensetzung der Oberen Elster-Grundmoräne in der Leipziger Tieflandsbucht (vgl. EISSMANN 1975) sind von der in Uichteritz anstehenden völlig verschieden. Die moderaten Kristallin-Werte, geringen Anteile an Paläozoi- 
Tab. 2: Kleingeschiebezählungen aus der Kiessandgrube Uichteritz (Fraktion 4 - 10 mm, Korn-\%). qsZ - Saale-Grundmoräne (Zeitzer Phase).

Tab. 2: Gravel analyses of till from the gravel and sand pit Uichteritz (grain size range $4-10 \mathrm{~mm}$, grain \%).

qsZ - Saalian till (Zeitz phase).

Bemerkungen: Kein Dolomit, kein Kreidekalk, viele Neubildungen (Kalk- und Kalk-/EisenhydroxidKrusten), einheim. Porphyre eckig, z. T. gebleicht, Trennung Paläoz. Kalkstein/Muschelkalk z. T. unsicher.

\begin{tabular}{|l|c|c|}
\hline Probennummer & Ui/G1 & Ui/G2 \\
\hline Stratigraphie & qsZ & qsZ \\
\hline GeschiebeanzahI & 923 & 488 \\
\hline Nord. Kristallin & 14,6 & 13,7 \\
\hline Paläoz. Kalkstein & 9,5 & 10,5 \\
\hline Dolomit & 0 & 0 \\
\hline Feuerstein, frisch & 3,1 & 3,1 \\
\hline Feuerstein, abgerollt, & 3 & 1,2 \\
verwittert & & \\
\hline Sandstein/Quarzit & 11,1 & 14,1 \\
\hline Quarz & 35,8 & 36,3 \\
\hline einheim. Porphyr & 13,7 & 14,3 \\
\hline Muschelkalk & 4,6 & 3,7 \\
\hline Kieselschiefer & 2,2 & 1,4 \\
\hline Schluff-/Tonstein & 0,4 & 0,4 \\
\hline Konglomerat & 0 & 0,2 \\
\hline Grauwacke & 0,3 & 0 \\
\hline Tonschiefer/Phyllit & 1,7 & 1 \\
\hline Summe & 100 & 99,9 \\
\hline Kohleton & 0,2 & 0 \\
\hline Neubildungen & 7,7 & ca. 60 \\
\hline
\end{tabular}

schem Kalkstein und die hohen Quarz-Gehalte (Tab. 2) sprechen dafür, den Geschiebemergel von Uichteritz als Bildung des ersten SaaleInlandeisvorstoßes (Zeitzer Phase) aufzufassen. An seiner Basis befinden sich der BöhlenLochauer Bänderton und Beckenschluffe (vgl. EISSMANN 1975).

Die Geröllzusammensetzung des kiesigen Schmelzwassersandes im Liegenden entspricht im Wesentlichen der Kieszusammensetzung der Grundmoräne, so dass die Sedimente als Vorschüttsande des ersten Saale-Eisvorstoßes anzusehen sind. Differenzen fallen besonders bei den Quarz-Gehalten auf, lassen sich aber auf die unterschiedlichen Zählfraktionen zurückführen (Tab. 1: Probe Ui/S9, Tab. 2).

Die mit Fließerde gefüllte Hohlform in der Südostecke der Kiessandgrube ist im Zeitraum zwischen der Verwitterung des Oberen Schotters und der Ablagerung der Beckenschluffe vor dem Saale-Eisrand entstanden, also vermutlich im unteren Teil des Saale-Komplexes.

Der Zeitraum vom Abschmelzen des ersten Saale-Inlandeises bis zur Eem-Warmzeit ist bei Uichteritz nicht durch Ablagerungen belegt. Die jüngsten, diskordant über den älteren Bildungen lagernden Sedimente sind verschwemmter und äolischer Löss aus der Weichsel-Kaltzeit.

\section{Paläoökologie}

Quartäre terrestrische und limnische Mollusken (Mollusca: Gastropoda, Bivalvia) sind geeignete Werkzeuge für paläoökologische Untersuchungen. Die Mollusken haben sich im Zeitraum des Quartärs nur wenig verändert. Fast alle im Quartär nachgewiesenen Arten existieren noch heute. Daraus ergibt sich die Möglichkeit, mit Hilfe aktualistischer Vergleiche der ökologischen Ansprüche von rezenten Mollusken wichtige Rückschlüsse auf die Umwelt- und Klimaverhältnisse des Quartärs zu gewinnen. Einige Arten besitzen zudem eine stratigraphische Bedeutung (z. B. LožEK 1964, MANiA 1973).

In den spätelster- (?), saale- und weichselkaltzeitlichen Sedimentfolgen sind 10 molluskenführende Horizonte ausgehalten worden (Abb. 4: Proben Ui/M1-10), aus denen insgesamt über 100 Liter Sediment entnommen und nach den üblichen Methoden zur Gewinnung von Molluskenschalen (z. B. nach LožEK 1964) durch Schlämmen, Sieben und Auslesen bear- 
beitet wurden. Im Ergebnis konnten insgesamt ca. 50 Arten und mind. 11730 Individuen gewonnen werden. Geborgen wurden auch einige Wirbeltierreste, die jedoch stark unterrepräsentiert und schlecht erhalten sind.

\subsection{Spätelster (?) von Uichteritz}

\subsubsection{Mollusken (Gastropoda, Bivalvia)}

Der Untere und der Obere Schotter lieferten bisher keine Molluskenreste und in den Verschwemmungsablagerungen treten nur sporadisch Relikte auf. Dagegen fanden sich in dem Mittleren Schotter sowie in Stillwassersedimenten (in vergleichbarer stratigraphischer Position) Anhäufungen von Molluskenresten.

Mittlerer Schotter: Der wahrscheinlich spätelsterzeitliche Schotter ist unregelmäßig verwittert und z. T. kalkfrei (Kap. 3). Mollusken sind deshalb nur in den weniger überprägten Bereichen erhalten, z. T. in Sandlinsen oder auch direkt in gröberen mit Schluff angereicherten Schottern (Abb. 5a: Profil 5: Ui/M1, Profil 2: Ui/M2, Profil 8: Ui/M3). Insgesamt ist der Mittlere Schotter verhältnismäßig arm an Molluskenresten. Bekannt ist deshalb nur ein schmaler Ausschnitt der Gesamtfauna. Geborgen wurden insgesamt ca. 35 Arten und mind. 245 Individuen. Auffällig hoch ist die Artenzahl im Verhältnis zur geringen Individuendichte. Dies verdeutlicht den allochthonen Charakter der vorgefundenen Taphozönose. Die Schalenreste sind überwiegend schlecht erhalten, was aufgrund der Transportdynamik in Flüssen typisch ist.

Am ergiebigsten war eine Sandlinse direkt über der nordischen Steinsohle (Profil 5: Ui/M1) im basalen Teil des Schotters. 10 Liter Sediment lieferten ca. 27 Arten und mind. 206 Individuen.

Die Fauna des Mittleren Schotters besteht zu ca.
$15 \%$ der Arten und ca. $41 \%$ der Individuen aus Fließgewässerarten, die vermutlich direkt in der Saale lebten. Bezeichnende Elemente sind die Napfschnecke Ancylus fluviatilis, die Kleinmuscheln Pisidium supinum, Pisidium moitessierianum, Pisidium cf. amnicum sowie die Flussmuschel Unio crassus. Von den Kleinmuscheln ist Pisidium supinum am strengsten an größere Flüsse gebunden. Unio crassus konnte, wenn auch nur in sehr schlechter Schalenerhaltung, mit doppelklappigen Exemplaren in Lebendstellung belegt werden. Planorbarius corneus, Bithynia sp. oder Radix cf. balthica (ehemals Radix ovata) bevorzugen stille und langsam fließende Gewässer und besiedelten möglicherweise die beruhigteren Strombuchten. Valvata macrostoma, Anisus leucostoma, Gyraulus crista und Gyraulus acronicus sind dagegen stärker an Stillgewässer gebunden. Vermutlich lebten sie in kleineren Gewässern, z. B. in Altarmbereichen innerhalb der ehemaligen Saaleaue. Von Bithynia sp. fehlen vollständige Gehäuse im Fossilbericht. Neben einigen Apexfragmenten sind überwiegend Deckel erhalten. Im Vergleich zu Bithynia tentaculata (Linnaeus 1758) sind die Deckel von Uichteritz an der Oberkante viel stärker abgerundet gewinkelt. Die Deckel von Bithynia leachii (SHePPARd 1823) sind dagegen an der Oberkante stark gerundet und max. nur sehr undeutlich gewinkelt. Die Gesamtform der Uichteritzer Exemplare ist zudem stark schüsselförmig. Die Deckel von Bithynia tentaculata sind hingegen in etwa an ihrer Längsachse aufgebogen und wirken leicht verdreht. Im Vergleich zur Uichteritzer Form besitzen Parafossarulus crassitesta (BRÖMme 1885) und Bithynia troschelii (PAAsCH 1842) sehr ähnlich ausgebildete Deckel (vgl. GittennberGer et al. 1998: Abb. 140-163, S. 96 und 100). Parafossarulus crassitesta wird immer wieder aus dem Alt- und Mittelpleistozän beschrieben, z. B. von Wendelstein in Sachsen-Anhalt (Wüst 1901a, Mania 1973), aus der Paludinenbank von Berlin (Schmierer i 923 , Heck 1930) oder 


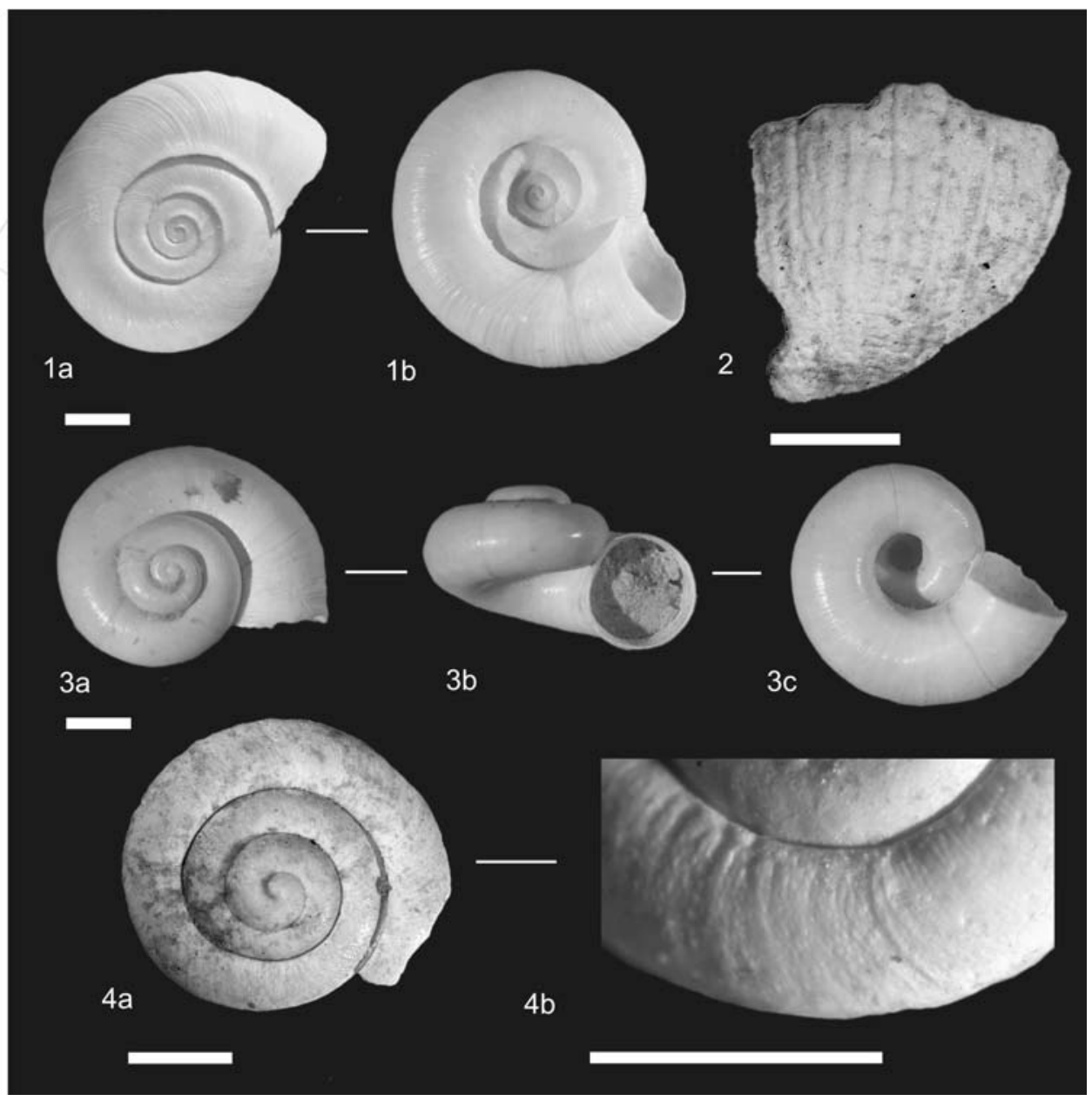

Tafel 1:

Abb. 1: Gyraulus acronicus; Uichteritz, Hauptfundschicht (Profil 1, Ui/M4).

Abb. 2: Ena montana, Gehäusefragment; Uichteritz, Mittlerer Schotter (Profil 5, Ui/M1).

Abb. 3 a-c: Valvata macrostoma; Uichteritz, Hauptfundschicht (Profil 1, Ui/M4).

Abb. 4 a-b: Monachoides incarnatus, Gehäusefragment; Uichteritz, Mittlerer Schotter (Profil 5, Ui/M1): a - Gesamtansicht, b - Ausschnitt Schalenskulptur.

Maßstabsbalken: jeweils $1 \mathrm{~mm}$

Fotos: Meng

Plate 1:

Fig. 1 a-b: Gyraulus acronicus; Uichteritz, main layer for finds (profile 1, Ui/M4).

Fig. 2: Ena montana, shell fragment; Uichteritz, Middle Gravel Unit (profile 5, Ui/M1).

Fig. 3 a-c: Valvata macrostoma; Uichteritz, main layer for finds (profile 1, Ui/M4).

Fig. 4 a-b: Monachoides incarnatus, shell fragment; Uichteritz, Middle Gravel Unit (profile 5, Ui/M1): a - complete view, b - detail of the shell sculpture.

scalebar: $1 \mathrm{~mm}$

photos: Meng 
aus den Mosbacher Sanden bei Wiesbaden in Hessen (GeIssert 1970). Bithynia troschelii, rezent im Wesentlichen osteuropäisch verbreitet, betrachtet GlÖER (2002 a, b) als östliche Rasse bzw. Unterart von Bithynia leachii.

Bemerkenswert hoch ist in der Fauna der Anteil an gehölzliebenden Arten (ca. 29 \% der Arten und ca. $13 \%$ der Individuen) mit Ena montana, Clausilia pumila, Perforatella bidentata, Discus ruderatus, Monachoides incarnatus, Fruticicola fruticum, Eucobresia diaphana und Carychium tridentatum u. a. Diese Gesellschaft verdeutlicht, dass wenigstens in der ehemaligen Saaleaue ausgedehntere Gehölzstrukturen vorhanden waren. Typische Vertreter der feuchteren Auenwälder sind beispielsweise die mittel- und osteuropäisch verbreiteten Arten Perforatella bidentata und Clausilia pumila. Anspruchsvollere Waldelemente sind Ena montana, mitteleuropäisch-alpin-karpatisch, sowie Monachoides incarnatus, mittel- und südosteuropäisch. Eucobresia diaphana ist rezent überwiegend montan verbreitet. Das paläarktische Element Discus ruderatus lebt heute in den borealen Wäldern Sibiriens und Skandinaviens, in den Alpen hauptsächlich oberhalb von 1000 m NN und seltener in den Kammlagen der Mittelgebirge. In der nördlichen Mongolei, im Selenga-Stromsystem, ist die Art ein ausgesprochen häufiger Bewohner der Auenwälder (S. Meng Aufsammlungen 1992). Fruticicola fruticum bevorzugt lichtere Gehölzstrukturen. Thermophile und exotische Waldelemente fehlen in der Uichteritz-Fauna.

Die Fragmente von Ena montana konnten durch die gitterartigen bis knötchenartigen Skulpturen auf der Schalenoberfläche bestimmt werden (Taf. 1, Fig. 2). Mit Hilfe eines charakteristischen Mündungsfragmentes konnte zudem eine Verwechslung mit den im Gesamthabitus ähnlichen Gehäusen von Chondrula tridens (O. F. MüLLER 1774) ausgeschlossen werden. Die mehrere Windungen zählenden Fragmente von Monachoides incarnatus sind wegen der winzigen, dicht aufgereihten, fast rautenförmigen Knötchen auf der Schalenoberfläche sicher zuordenbar (Taf. 1, Fig. 4).

Eine breite ökologische Amplitude, von Wald bis Offenland und von mesophil bis schwach hygrophil, besitzen Trichia cf. hispida und Cochlicopa lubrica. Stärker hygrophile Habitate bevorzugen dagegen Vertigo antivertigo, Vitrea crystallina und Vallonia pulchella. Komponenten des Offenlandes, hauptsächlich mesophiler Standorte, sind Vertigo pygmaea und Vallonia costata. Besonders häufig ist Vallonia costata. Von den terrestrischen Schnecken bildet die Art über $40 \%$ der Gesamtindividuendichte. $\mathrm{Zu}$ bemerken ist allerdings, dass ihre kleinen festschaligen Gehäuse ausgezeichnet für den unbeschadeten Transport im Wasser geeignet sind und deshalb Flussgeniste schneller dominieren können als andere Arten. Ausgesprochene Steppenelemente sind bisher nur durch cf. Helicopsis striata vertreten.

Insgesamt fehlen im Mittleren Schotter Kaltzeitleitformen sowie Leitarten für Interglaziale. Der boreo-alpine Discus ruderatus spricht für kühlere Klimabedingungen. Die Art findet sich vor allem in den Übergangsphasen von Warmzu Kaltzeiten. Während für den ehemaligen Auenbereich der Saale ausgedehntere Auenwaldstrukturen und offenere Gebiete mit Wiesen und Feuchthabitaten sowie Stillgewässern (z. B. Altarmbereiche) anzunehmen sind, fehlt über das weitere Umfeld außerhalb der Aue eine gesicherte Datenbasis. Abhängig ist das Problem von den taphonomischen Verhältnissen, bezüglich der Überlieferung von Molluskenresten im Ablagerungsraum innerhalb des ehemaligen Auensystems der Saale. Das zahlreichere Auftreten von einigen Komponenten des Offenlandes erlaubt zumindest den Schluss, dass keine geschlossene Bewaldung vorhanden war. Problematisch ist, dass man bei der Interpretation der damaligen Umweltbedingungen, bezüglich des Indikatorwertes von Mollusken, dazu geneigt ist, die Verhältnisse mit denen des 
heutigen Mitteleuropas vergleichen zu wollen. Dabei darf aber nicht vergessen werden, dass sich unter verstärktem kontinentalen Einfluss der Habitatbezug einiger Molluskenarten verschieben kann. So bilden sicherlich Auen in Steppen- bzw. Waldsteppengebieten für viele Arten wertvolle Rückzugsgebiete.

Stillwassersedimente: Die Folge von schluffigtonigen Sedimenten im Südwesten der Grube (Profil 1) akkumulierte vermutlich im Bereich eines Altarmes am Rand der spätelsterzeitlichen (?) Saaleaue. Die feinkörnigen Ablagerungen schalten sich zwischen den Mittleren Schotter und schwemmfächerartige Sedimente ein, die sich mit dem Oberen Schotter verzahnen (Abb. 5c). Aus der ansonsten steril wirkenden Sedimentfolge konnten aus einem 15-30 cm mächtigen graublauen Schluffhorizont, aus 35 Litern Probenmaterial, über 11000 Molluskenschalen mit ca. 33 Arten geborgen werden (Abb. 5a: Profil 1: Ui/M4). Die Schalen sind meist sehr gut erhalten.

Dominiert wird die Fauna erwartungsgemäß durch einen sehr hohen Anteil von Stillwasserbewohnern (ca. $81 \%$ der Individuendichte und ca. $33 \%$ der Artendichte): Valvata macrostoma (Taf. 1, Fig. 3), Stagnicola spp., Anisus leucostoma, Gyraulus acronicus (Taf. 1, Fig. 1), Gyraulus crista, Aplexa hypnorum, Galba truncatula, Planorbis planorbis und die Kleinmuscheln Pisidium obtusale f. lapponicum, Pisidium milium sowie Pisidium globulare. Auch die weniger spezialisierten Schnecken Radix cf. balthica und Lymnaea stagnalis sowie die Kleinmuschel Pisidium nitidum charakterisieren diese Gesellschaft. Ausgesprochene Fließgewässerarten fehlen, was den überwiegend autochthonen Charakter dieser Thaphozönose verdeutlicht. Ein typischer Bewohner der Auen größerer Ströme ist vor allem Valvata macrostoma (vgl. GLÖER 2002 b). Temporäre Gewässer bevorzugt Aplexa hypnorum. Pisidium obtusale ist durch die Reaktionsform lapponicum vertre- ten, einem Indikator für kaltzeitliches Klima (Kuiper 1968). Pisidium globulare, ehemals als Form von Pisidium casertanum (Poli 1791) angesehen, erhielt erst vor einigen Jahren erneuten Artstatus (Korniushin 1998). Aus dem Quartär wurden deshalb von dieser Art bisher nur wenige Vorkommen beschrieben (BössNeCK \& Meng 2005).

Der Genus Stagnicola zeichnet sich in der Fauna von Uichteritz durch eine große Formenvielfalt aus. Möglicherweise sind mehrere Arten vorhanden. Die Determination von Stagnicola-Arten, nur mit Hilfe conchiologischer Merkmale, ist problematisch. Sie erfolgt bei rezenten Arten mittels genitalanatomischer Untersuchungen (vgl. GLÖER 2002b).

Landschnecken stellen zwar ca. $65 \%$ des Artenspektrums, aber nur etwa $17 \%$ der Individuendichte. Davon fallen allein fast $80 \%$ der Individuen auf die stark hygrophilen Elemente Oxyloma sp., Carychium minimum, Cochlicopa nitens, Vertigo antivertigo und Vallonia enniensis. Die Arten lebten vermutlich in unmittelbarer Nähe des Stillgewässers. Im Fundhorizont erhaltene Kalk-Hohlraum-Inkrustate von Schilfstengeln bieten weitere Anhaltspunkte für die Charakterisierung des Habitats. Mit Perforatella bidentata, Clausilia pumila, Vertigo substriata, Perpolita petronella und Fruticicola fruticum sind wiederum gehölzliebende Elemente vorhanden, ebenso wurden die Ubiquisten Cochlicopa lubrica, Punctum pygmaeum, und Trichia cf. hispida nachgewiesen.

Offene Habitate bevorzugen z. B. Succinella oblonga, Vallonia costata und Pupilla muscorum. Sie bilden $14 \%$ der Gesamtindividuendichte der terrestrischen Schnecken. Succinella oblonga gilt zwar als typisches Element für die kaltzeitlichen „trockenen“ Lösssteppen, bevorzugt aber rezent in Mitteleuropa feuchtere Habitate und findet sich auch z. T. im Gehölz. Die bekannte "Lössschnecke“ Pupilla muscorum, rezent in Mitteleuropa eher ein Bewohner offener und trockenerer Standorte, besitzt unter kontinen- 
taleren Bedingungen deutliche Präferenzen für feuchtere Habitate (Erfahrungen von S. Meng in Zentralasien: Baikalgebiet, Sibirische Altai, Tienschan). Diese offenbar widersprüchlichen Fakten erschweren die Rekonstruktion der ehemaligen Umweltverhältnisse. Vor allem Wiesen mit verschiedenen Feuchtegehalten, möglicherweise auch innerhalb der ehemaligen Saaleaue und nicht nur auf das trockenere Umland beschränkt, kommen für diese Arten als Lebensraum in Frage. Steppenelemente wurden bisher in den Stillwassersedimenten nicht nachgewiesen.

Ein echtes Kaltzeitelement ist mit der arktisch (subarktisch)-alpinen Schnecke Columella columella vorhanden. Die Art bevorzugt feuchtere kaltzeitliche Abschnitte (bzw. adäquate Habitate). Columella columella wird meist als Offenlandart interpretiert, lebt aber z. T. auch im Wald (z. B. im Sibirischen Altai, Aufsammlungen S. Meng 1995). Von großem Interesse ist der Nachweis von Eucobresia nivalis, denn aus dem Pleistozän wird die Art nur selten erwähnt. RÄHLE (1977) berichtete über ein Vorkommen in der Burghöhle Dietfurt bei Sigmaringen (Schwäbische Alb) in weichselspätglazialen Bildungen. Die Schnecke ist alpin und karpatisch verbreitet. Besonders in hochalpinen Bereichen ist sie häufig. Seltener findet sie sich in den Kammlagen der Mittelgebirge. Eucobresia nivalis bevorzugt feuchtere Habitate. Beide Arten sind ebenfalls potentielle Bewohner der ehemaligen Saaleaue. Für kühlere Bedingungen spricht ebenfalls die Anwesenheit der boreoalpinen Elemente Gyraulus acronicus, Perpolita petronella und Vertigo substriata.

Von Eucobresia nivalis liegt ein beschädigtes Gehäuse vor. Aufgrund des deutlich erhabenen Gewindes und des deutlich schmaleren sog. Hautsaumes auf der Unterseite des Gehäuses ist es gut von Eucobresia diaphana unterscheidbar. Für Semilimax kochi (Andreae 1884), gelegentlich für das ältere Pleistozän erwähnt (zusammenfassend RäHLE \& BibUS 1992), nachgewiesen z. B. in Süßenborn bei Weimar in Thüringen (ZeIssler 1969), fanden sich in Uichteritz keine Hinweise. Die Art ist nach bisherigen Kenntnissen im mittleren Pleistozän erloschen.

Die Fauna der Stillwassersedimente erlaubt ebenfalls eine Rekonstruktion der ehemaligen Saaleaue. Neben Stillgewässern, vermutlich verlandenden Altarmbereichen, Feuchthabitaten, z. T. mit Schilfbeständen, waren Wiesen sowie Auenwaldstrukturen entwickelt. Nachweise von Offenlandarten sowie von Kaltzeitelementen machen es wieder wahrscheinlich, dass außerhalb der Aue keine geschlossene Bewaldung vorhanden war. Das Fehlen von Steppenelementen innerhalb einer relativ autochthonen Molluskengesellschaft der ehemaligen Saaleaue wird als ein Problem der fehlenden Überlieferung gedeutet.

Gesamtfauna: Abgesehen von lokalen faziesbedingten Unterschieden in der Zusammensetzung der Faunen deuten die Mollusken des Mittleren Schotters sowie der verzahnten Stillwassersedimente auf einen ganz ähnlichen paläoökologischen Rahmen (Abb. 11). Die Dominanz an gehölzliebenden Arten ist im Mittleren Schotter im Vergleich zu den Altarmsedimenten etwas höher, was mit dem Lebensraum im Umfeld des Ablagerungsraumes und dem allochthonen Charakter der Taphozönose erklärt werden kann.

Mitunter repräsentieren die Stillwassersedimente im Vergleich zum Mittleren Schotter eine etwas kühlere klimatische Phase, insbesondere wegen des Auftretens von Columella columella und Eucobresia nivalis, wobei keinesfalls lokal bedingte faunistische Unterschiede sicher auszuschließen sind. Interglaziale Bedingungen können auch durch das Fehlen von Cepaea und Helix ausgeschlossen werden, welche in sämtlichen bekannten mitteleuropäischen Interglazialen nachgewiesen wurden (JäGER \& LožEK 2004). Insgesamt war das Klima im Vergleich 

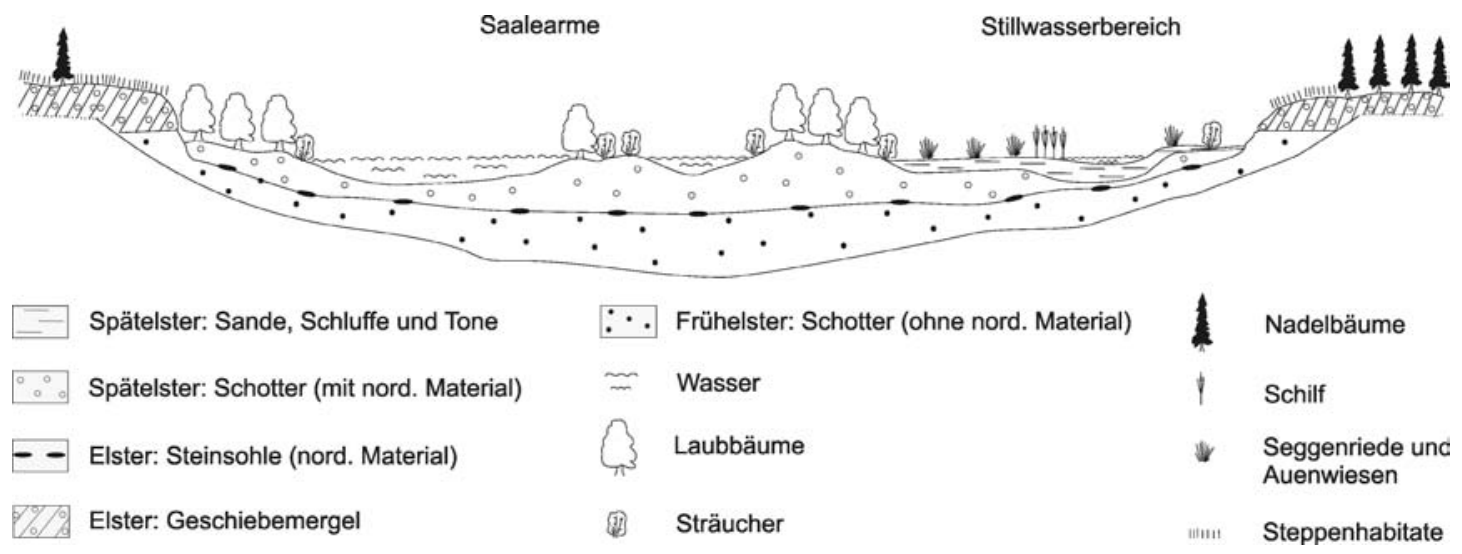

Abb. 11: Rekonstruktion der spätelsterzeitlichen Saaleaue bei Uichteritz (überhöht).

Fig. 11: Reconstruction of the late Elsterian Saale floodplain near Uichteritz (exaggerated).

zu den heutigen mitteleuropäischen Verhältnissen kühler und stärker kontinental geprägt und kann als kaltgemäßigt charakterisiert werden.

\subsubsection{Wirbeltierreste (Pisces, Aves, Mammalia)}

In den Schottern und Verschwemmungsablagerungen fanden sich gelegentlich Wirbeltierreste. In der Gesamtfauna sind sie bis jetzt leider nur spärlich vertreten.

Fische: Im Mittleren Schotter (Profil 5: Ui/M1) konnten einige Wirbelkörper von kleinen Cypriniden nachgewiesen werden.

Vögel: Aus den Stillwassersedimenten (Profil 1: Ui/M4) wurden zahlreiche Eierschalen-Fragmente von Vögeln separiert. Ihre Dünnschaligkeit legte zunächst den Verdacht nahe, dass es sich um Reste von Schildkröteneiern handeln könnte. Rasterelektronenmikroskopische Untersuchungen von S. Meng zur Feinstruktur der Schalen, in Anlehnung an Erben (1970) und Böнme (2001), widerlegten jedoch den Verdacht.
Kleinsäuger: In den Stillwassersedimenten (Profil 1: Ui/M1) fand sich lediglich ein Molar von Microtus sp. Hinzu kommen einige unbestimmbare Fragmente mehrerer Inzisiven.

Großsäuger: Gespräche mit Kiesgrubenarbeitern und mit Bodendenkmalpflegern ergaben, dass in der Kiessandgrube Uichteritz offenbar noch keine bedeutenderen Großsäugerreste geborgen wurden. Den Verfassern gelang leider nur der Nachweis von kleineren schlecht erhaltenen Knochenfragmenten, z. B. im Mittleren (Profil 5) und Oberen Schotter (Profil 7), welche bisher nicht näher determiniert wurden.

\subsection{Vergleichbare mittelpleistozäne Molluskenfaunen}

In der mitteleuropäischen Literatur finden sich zu elsterzeitlichen (bzw. mindelzeitlichen) Molluskenfaunen nur wenige Hinweise. Überwiegend handelt es sich um hochkaltzeitliche Assoziationen mit Pupilla spp.-Succinella oblonga- sowie Columella columella-Gesellschaften (ZÁrubA et al. I962, LožEK 1964, 1989, MüNZING 1968, 1969, Mania 1973, EIssmann 1975). 
Größere Übereinstimmung mit Uichteritz besitzen dagegen die mittelpleistozänen Faunen von Süßenborn bei Weimar (Thüringen) sowie von Mosbach bei Wiesbaden (Hessen).

Eine reiche und bedeutende, wahrscheinlich cromerzeitliche Molluskenfauna ist aus den Ilmschottern von Süßenborn bekannt geworden (Weiss 1899, WÜst 1901a, Zeissler 1969, Mania 1973). Berühmt wurden die Schotter vor allem wegen ihres reichen Wirbeltierinventars (KAHLKe 1969, KahlKe 2002). Nach dem Vorkommen des Kleinsäugers Mimomys savini, sind zumindest die älteren Schotterteile älter als das Interglazial Cromer III (HeINRICH 2000, Maul 2002) zu datieren. Die detaillierte stratigraphische Zuordnung, insbesondere der Molluskenfunde, ist jedoch bis heute unsicher. Die umfangreichste Neubearbeitung der Mollusken erfolgte von Zeissler (1969). Die Untersuchungen konzentrierten sich hauptsächlich auf die Unteren Kiese. Die sog. Älteren Schotter im Liegenden konnten nicht berücksichtigt werden.

Die ca. 50 Arten umfassende Fauna beschreibt im Vergleich zu Uichteritz, z. B. durch das gemeinsame Auftreten von Kaltzeitelementen: Columella columella, Vallonia tenuilabris, Pisidium obtusale f. lapponicum mit gehölzliebenden Arten: Perforatella bidentata, Discus ruderatus, Vitrea crystallina, Clausilia pumila, Fruticicola fruticum u. a. sowie zahlreichen Offenlandelementen, ganz ähnliche paläoökologische Verhältnisse. Wüsт (1901a) erwähnte von Süßenborn auch das anspruchsvollere Gehölzelement Ena montana.

Nicht unerwähnt bleiben soll in diesem Zusammenhang die berühmte quartärpaläontologische Fundstätte Mosbacher Sande. Die Folgen sind überwiegend cromerzeitlich einzuordnen, wobei die stratigraphischen Einstufungen auch an dieser Lokalität unsicher sind (BRÜNING 1970, Keller 2004). Aus den Oberen Mosbacher Sanden (Mosbach 2) wurden reiche Molluskenfaunen nachgewiesen. Die Bearbeitung dieser
Faunen übernahmen vor allem Wüst (1901a) und Geissert (1970). Die Folge Mosbach 2 ist durch das älteste Auftreten der Kleinsäugergattung Arvicula gekennzeichnet, was die Einordnung in das späte Cromer erlaubt (Maul et al. 2000, Keller 2004). Die Molluskenfauna aus den Oberen Mosbacher Sanden besitzt ebenfalls im Vergleich mit Uichteritz ein ähnliches Faunengepräge. Bekannte Elemente sind beispielsweise Valvata macrostoma, Aplexa hypnorum, Columella columella, Vallonia costata, Vallonia pulchella, Succinella oblonga, Oxyloma elegans, Cochlicopa lubrica, Cochlicopa nitens, Vertigo antivertigo, Vertigo pygmaea, Vitrea crystallina, Ena montana, Discus ruderatus, Clausilia pumila, Perforatella bidentata, Fruticicola fruticum, Trichia spp. u. a.

Die Molluskenfaunen von Süßenborn und Mosbach sind zwar zeitlich mit Uichteritz nicht identisch, aber sie charakterisieren mittelpleistozäne Verhältnisse, dessen rekonstruierte Landschaftsbilder durch ihre Ähnlichkeit bestechen. Die Faunen sind ebenfalls durch kühlere und stärker kontinentale Verhältnisse geprägt.

\subsection{Saalekaltzeitliche Mollusken von Uichteritz}

Aus den im Hangenden der Schotter folgenden glaziären Serien des Saale-Komplexes (DrentheStadium) wurden Mollusken nachgewiesen. Es handelt sich um artenarme hochkaltzeitliche Gesellschaften, welche auch für Lössbildungen typisch sind.

Eisstauseebildungen: Die über den Schottern lagernden ca. $1 \mathrm{~m}$ mächtigen Beckenschluffe führen an ihrer Basis, in kiesvermengten Schluffen lokal Succinella oblonga (Profil 5: Ui/M6). Weiterhin fanden sich Pupilla muscorum und Succinella oblonga in bis zu $15 \mathrm{~cm}$ mächtigen blaugrauen Schluffen, welche in Profil 5 (Probe 


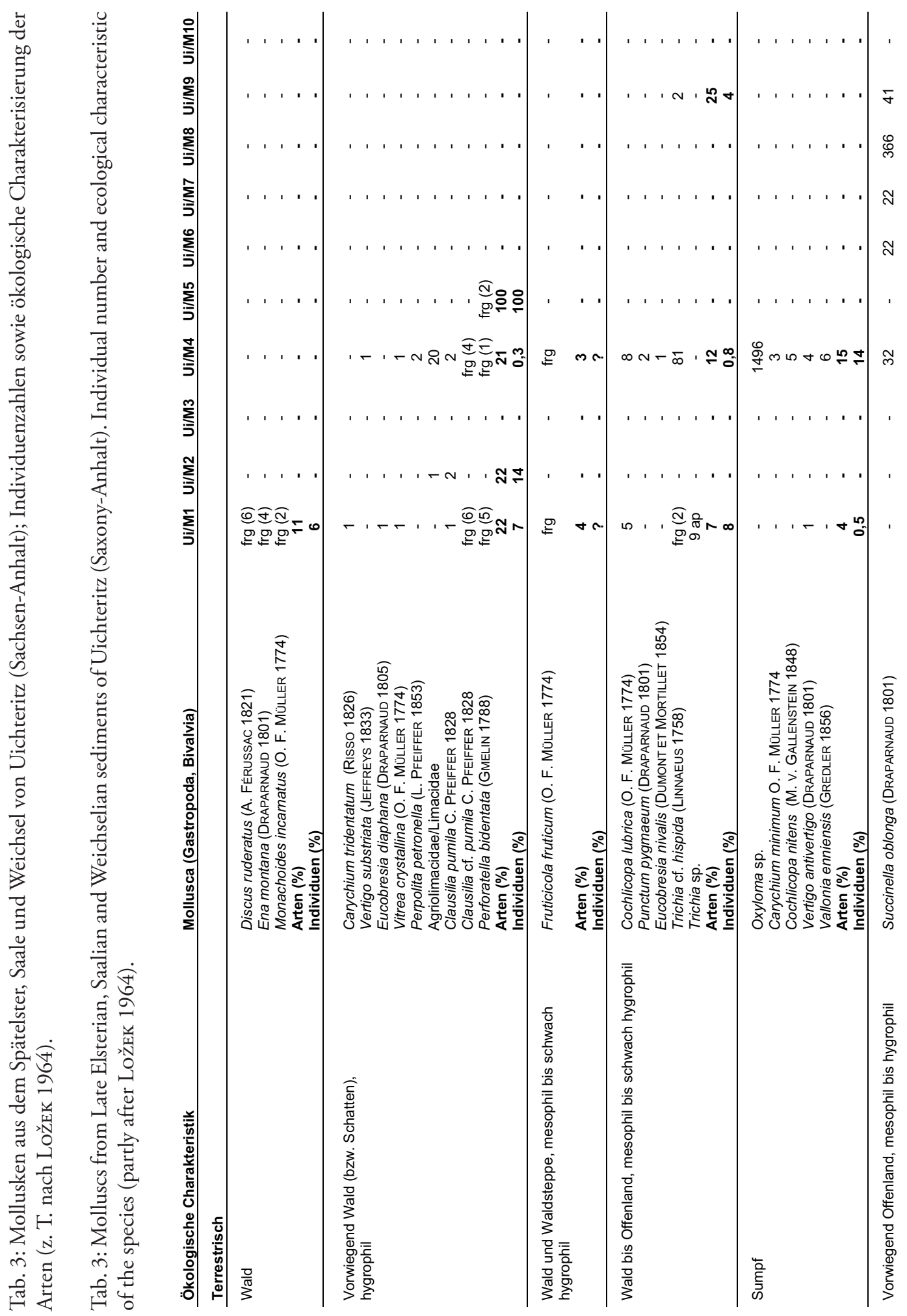




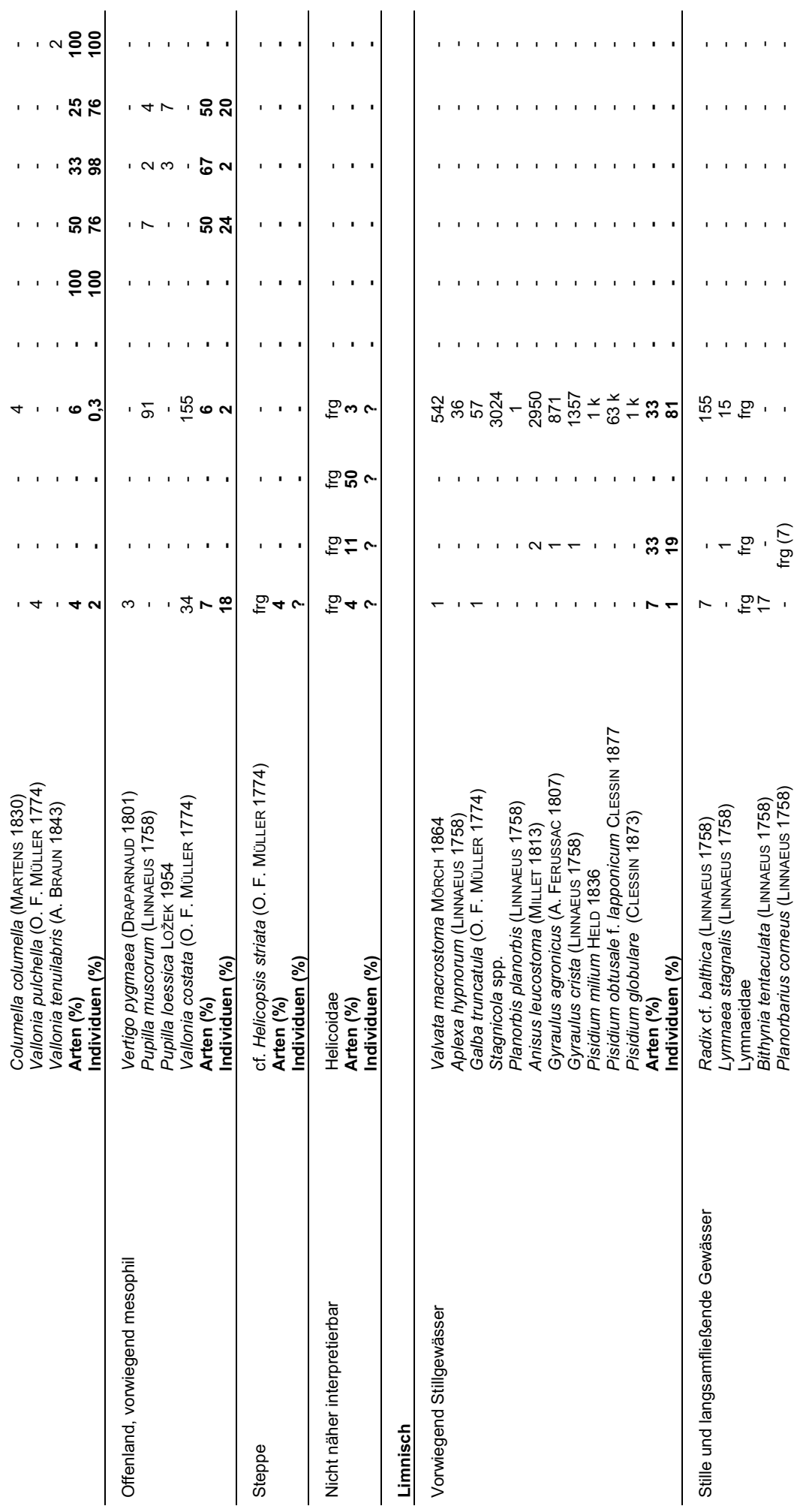




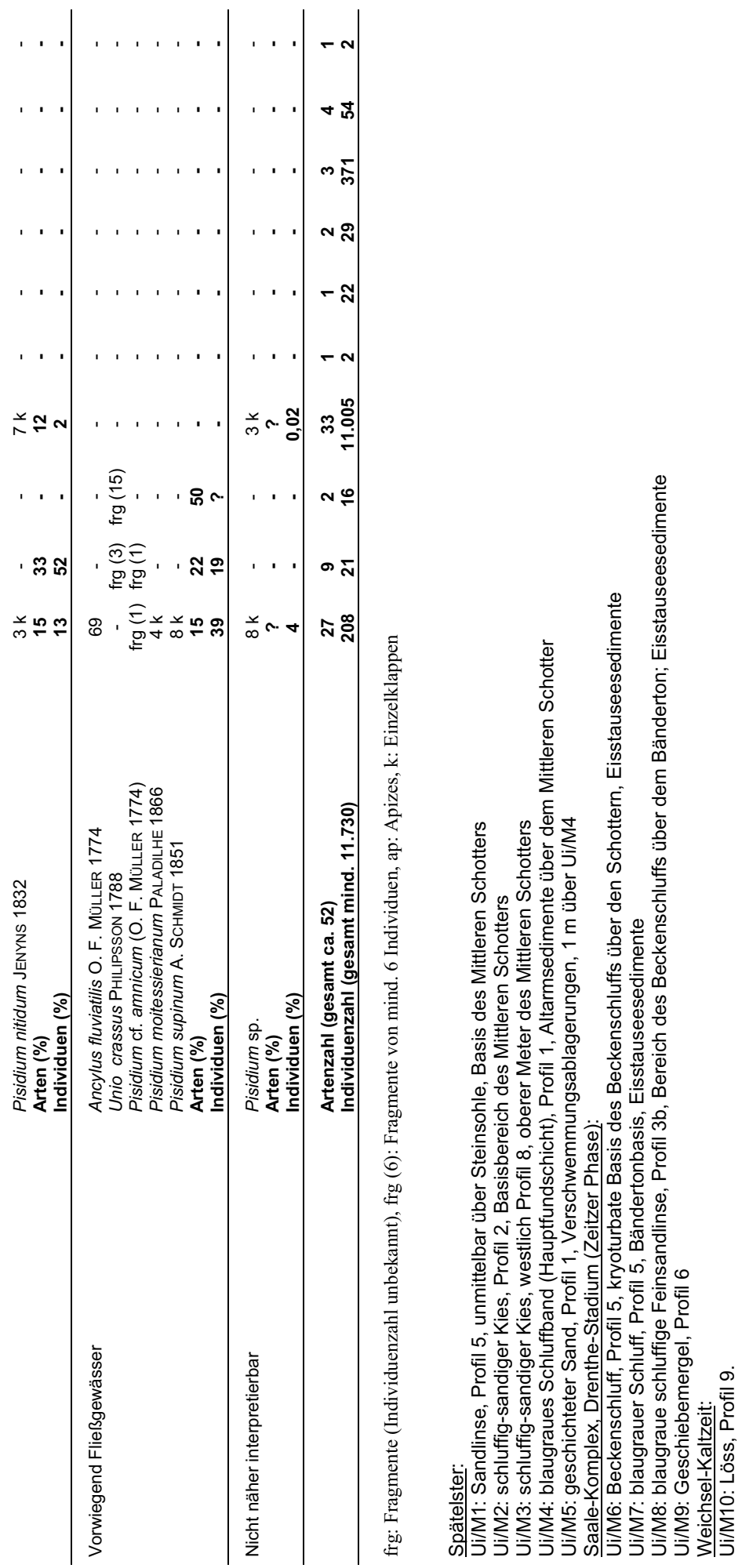


Ui/M7) an der Obergrenze des Schluffpaketes, unmittelbar an der Basis des Warvits (Bänderton), entwickelt sind.

Blaugraue und hellgrünlich-graue schluffige Sande mit reicher Molluskenführung sind lo$\mathrm{kal}$ in den bis $1 \mathrm{~m}$ mächtigen Beckenschluffen oberhalb des Warvits linsenförmig eingeschaltet (Profil 3b, Ui/M8). Neben Succinella oblonga und Pupilla muscorum enthält die Fauna Pupilla loessica.

Geschiebemergel: Auch der bis zu $3 \mathrm{~m}$ mächtige Geschiebemergel im Hangenden ist schneckenführend (Profil 6: Ui/M9). Die Gehäuse sind erstaunlicherweise ausgezeichnet erhalten. Besonders an den angewitterten Grubenwänden sind sie in der gesamten Mächtigkeit des Geschiebemergels regelmäßig zu finden. Die Schnecken sind nicht lokal angehäuft, sondern relativ gleichmäßig im Sediment verteilt. Die Entnahme einer Sedimentprobe war deshalb weniger ergiebig. Etwa 30 Liter Geschiebemergel lieferten nur 35 Gehäuse. Nachgewiesen wurden Succinella oblonga, Pupilla muscorum, Pupilla loessica sowie Trichia cf. hispida.

Fauneninhalte in glazigenen Sedimenten erscheinen zunächst als Kuriosum, sind aber relativ verbreitet (vgl. Kap. 3.1). Prenzel (1967), Mania (1973) und Eissmann (1975) beschrieben z. B. hochkaltzeitliche Molluskenfaunen aus dem Tagebau Roßbach bei Weißenfels (Sachsen-Anhalt), welche aus elsterzeitlichen Beckenschluffen unter dem Dehlitz-Leipziger Bänderton geborgen wurden. Es handelt sich um typische hochkaltzeitliche Assoziationen von Pupilla muscorum densegyrata LožEK 1954, Succinella oblonga, Columella columella, Gyraulus acronicus u. a. Nach Prenzel (1967) und Mania (1973) fanden sich die Mollusken auch direkt im Bänderton.

Aus Bändertonen selbst wurden immer wieder reiche Ichnofaunengesellschaften von Arthropoden bekannt. Hannemann (1965) sowie WaLter \& Suhr (1998) beschrieben Beispiele aus Sachsen-Anhalt, Sachsen und Brandenburg.

\subsection{Weichselkaltzeitliche Mollusken von Uichteritz}

Im Top der Grubenprofile ist z. T. weichselzeitlicher Löss entwickelt. Nur beim direkten Absuchen der Aufschlusswände konnten zwei Gehäuse von Vallonia tenuilabris nachgewiesen werden (Profil 9: Ui/M10). Dagegen erbrachte das Ausschlämmen von ca. 20 Litern Sediment kein Ergebnis. Die heute zentralasiatisch-sibirisch verbreitete Kaltzeitleitform Vallonia tenuilabris ist im mitteldeutschen Raum keine ausgesprochene Lössschnecke (MeNG 1995, 1998). Diese Art bevorzugt feuchtere kaltzeitliche Phasen (bzw. adäquate Habitate).

\section{Dank}

Die Arbeiten wurden auf Anregung von Prof. Dr. L. Eißmann, Sächsische Akademie der Wissenschaften zu Leipzig, durchgeführt, dem die Verfasser auch für ausführliche Erläuterungen und Problemdiskussionen zum Quartär des Untersuchungsgebietes und des näheren Umfeldes großen Dank schulden. Für Informationen und anregende Diskussionen zur Geologie und Archäologie im Markröhlitzer Tal danken wir ebenso A. Rudolph, ehrenamtlicher Bodendenkmalpfleger aus Leipzig, Dr. habil. T. Weber, Landesamt für Denkmalpflege und Archäologie Sachsen-Anhalt, Außenstelle Magdeburg, Prof. Dr. D. Schäfer, Institut für Hochgebirgsforschung und Alpenländische Land- und Forstwirtschaft der Universität Innsbruck, Dr. G. Beutler, Dr. C.-H. Friedel und P. Karpe, Landesamt für Geologie und Bergwesen Sachsen-Anhalt (LAGB), Halle, und 
Dr. L. Katzschmann, Thüringer Landesanstalt für Umwelt und Geologie, Außenstelle Weimar. Nebenbei sei erwähnt, dass T. Weber auf einer gemeinsamen Befahrung ein kleines Artefakt (Abschlag) im Verwitterungsbereich des Mittleren Schotters gefunden hat.

Die Bestimmung der Kleinmuscheln (Pisidium) übernahm Dr. U. Bößneck, Erfurt. Einige Gehäuse der Süßwasserschnecke Gyraulus acronicus überprüfte Dr. C. Meier-Brook, Ammerbuch. Die Kleinsäugerreste wurden von Dr. L. Maul, Weimar, und die Fischreste von Dr. G. Böhme, Berlin, untersucht. Die Dünnschliff-Untersuchung des Bt-Horizontes hat C. Büchner, LAGB Sachsen-Anhalt, Halle, durchgeführt. Die Kornverteilungen und Kalkgehalte wurden von C. Fleischer bzw. S. Nowak, LAGB Sachsen-Anhalt, Halle, ermittelt. G. Müller, Halle, hat maßgebend an der Gestaltung der PC-Graphiken mitgewirkt. Prof. Dr. I. Lerche, Halle, hat die englische Übersetzung überarbeit. Die Autoren möchten sich bei allen Beteiligten herzlichst bedanken.

Besonderer Dank gilt auch den Mitarbeitern der Firma H. Antons \& Sohn, Jülich, die den Zugang zum Grubengelände jederzeit genehmigt und die Arbeiten durch das maschinelle Anlegen von Schürfen aktiv unterstützt haben. P. Karpe, LAGB Sachsen-Anhalt, Halle, sowie der Fa. TERRA MONTAN Gesellschaft für angewandte Geologie $\mathrm{mbH}$, Suhl, sei für die Bereitstellung von Unterlagen zur Geologie der Kiessandlagerstätte Uichteritz gedankt.

\section{Literatur}

Baettenstaedt, F. (1934): Stauseebildung und Vorstoß des diluvialen Inlandeises in seinem Randgebiet bei Halle a. S. - Jb. Hallesch. Verb., N. F., 13: 241-315; Halle.

Böнme, G. (2001): Eigelege der Sumpfschildkröde Emys orbicularis LinnaEus, 1758, aus dem mittelpleistozänen Travertin von Bilzingsleben. - Praehistoria Thuringica, 6/7: 39-45; Artern.

Bössneck, H. \& Meng, S. (2005): Beitrag zur pleistozänen Muschelfauna Mitteldeutschlands unter besonderer Berücksichtigung der Spaeriidae (Bivalvia: Sphaeriidae, Unionidae, Corbiculidae). - Heldia, 6: 287-299; München (im Druck).

BRÜNING, H. (1970): Zur Klima-Stratigraphie der pleistozänen Mosbacher Sande bei Wiesbaden (Hessen). - Mainzer Naturw. Arch., 9: 204-256; Mainz.

Eissmann, L. (1964): Die alt- und frühpleistozänen Schotterterrassen der Leipziger Tieflandsbucht und des angrenzenden Gebietes. - Geologie, 13, Beih. 46: 1-93; Berlin.

Eissmann, L. (1975): Das Quartär der Leipziger Tieflandsbucht und angrenzender Gebiete um Saale und Elbe. - Schriftenr. geol. Wiss., 2: 1-263; Berlin.

Eissmann, L. (1994): Grundzüge der Quartärgeologie Mitteldeutschlands (Sachsen, Sachsen-Anhalt, Südbrandenburg, Thüringen). - Altenbg. nat. wiss. Forsch., 7: 55-135; Altenburg.

Erben, H. K. (1970): Ultrastrukturen und Mineralisation rezenter und fossiler Eischalen bei Vögeln und Reptilien. - Biomineralisation, 1: 1-66; Stuttgart, New York.

Fantasny, D. (1996): Ergebnisbericht über die Aufsuchung des Kiesvorkommens Uichteritz/ Lobitzsch. - TERRA MONTAN Ges. f. angew. Geol. mbH (unveröff.).

Geissert, F. (1970): Mollusken aus den Pleistozänen Mosbacher Sanden bei Wiesbaden (Hessen). - Mainzer Naturw. Arch., 9: 147203; Mainz.

Gittenberger, E., Janssen, A. W., Kuiper, J. G. J., Meijer, T., van der Velde, G., de Fries, J. N. \& Peeters, G. A. (1998): De Nederlandse Zoetwatermollusken. Recente en fossiele Weekdieren uit Zoet en Brak Water. - In: Gittenberger, E. \& Janssen, 
A. W. (Hrsg.) Nederlandse Fauna, 2: 288 S.; Leiden.

GlöER, P. (2002 a): Bithynia leachii troschelii (PAASCH 1842) - die östliche Rasse von $B$. leachii (Sheppard 1823). - Arch. f. Molluskenkunde, 130 (1/2): 259-265; Frankfurt a. M.

GLÖER, P. (2002 b): Die Süßwassergastropoden Nord- und Mitteleuropas. - Die Tierwelt Deutschlands, Teil 73: 327 S.; Hackenheim.

Haase, G., Lieberoth, I. \& Ruske, R. unter Mitarbeit von Altermann, M., Rau, D., Unger, K.-P. \& WÜNsche, M. (1970): Sedimente und Paläoböden im Lößgebiet. - In: Periglazial - Löß - Paläolithikum im Jungpleistozän der Deutschen Demokratischen Republik. - Peterm. Geogr. Mitt., Erg.-H. 274: 99-212; Gotha/Leipzig.

Hannemann, M. (1965): Schreitspuren in elsterkaltzeitlichen Bändertonen der Bohrung XV/61 bei Müllrose (Ostbrandenburg). - Geologie, 14: 110-113; Berlin.

Heck, H. L. (1930): Zur Fosilführung der Berliner Paludinenschichten, ihre Beschaffenheit und Verbreitung. - Z. dt. geol. Ges., 87: 386-404; Berlin.

HeIn Rich, W.-D. (2000): Rodentier-Biostratigraphie und Altersstellung der mittelpleistozänen Homo erectus-Schichten der Travertinfundstätte Bilzingsleben II in Thüringen, Mitteldeutschland. - Praehistoria Thuringica, 4: 28-40; Artern.

JäGeR, K.-D. \& LožEK, V. (2004): On the practicability of palaeomalacological criteria for dating Pleistocene interglacial sites in Central Europe. - Veröffentlichungen des Landesamtes für Archäologie, B 57: $273-$ 280; Halle.

Kahlke, H.-D. (Hrsg.) (1969): Das Pleistozän von Süßenborn. - Paläontologische Abhandlungen, A III (4/4): 367-788; Berlin.

KahlKe, R.-D. (2002): The Quaternary large mammal faunas of Thuringia (Central Germany). - In: Meyrick, R. A. \& Schreve D.
C. (Hrsg.): The Quaternary of Central Germany. Field Guide. Quaternary Research Association: 59-78; London.

Keller, T. (2004): Sedimentology and taphonomy of the Middle Pleistocene Mosbach Sands (Germany). - $18^{\text {th }}$ International Senckenberg Conference. VI International Palaeontological Colloquium in Weimar. Conference Volume. - Terra Nostra, 2004/ 2: 131-132.

Knoth, W. (1964): Zur Kenntnis der pleistozänen Mittelterrassen der Saale und Mulde nördlich von Halle. - Geologie, 13: 598616, Berlin.

Knoth, W. (1995): Sachsen-Anhalt. - In: Benda, L. (Hrsg.): Das Quartär Deutschlands. - 148-170; Berlin/Stuttgart (Gebr. Borntraeger).

Knoth, W. \& Lenk, G. (1962): Das Pleistozänprofil des Tagebaues Edderitz. - Geologie, 11: 1149-1161; Berlin.

Korniushin, A. V. (1998): On the identity of the anatomically distinct form of Pisidium casertanum (PouI) $(=P$. roseum sensu Korniushin 1995). - Heldia, 2: 133-135; München.

Kugler, H. (1961): Bemerkungen zur Gliederung und Altersstellung der pleistozänen Flußterrassen der Unstrut. - Geogr. Ber., 6: 183-196; Berlin.

Kuiper, J. G. J. (1968): Die spätpleistozänen Pisidien des ehemaligen Ascherslebener Sees. - Archiv f. Molluskenkunde, 98: 2338; Frankfurt a. M.

Lavrušin, J. A. (1978): Texturen, Fazies und stoffliche Zusammensetzung der Grundmoränen. - Schriftenr. geol. Wiss., 9: 161-177; Berlin.

Lehmann, H. \& Lehmann, R. (1930): Die diluvialen Flussterrassen in der Umgebung von Halle a.d.S. - Leopoldina, 6: 233-251; Leipzig.

Lehmann, R. (1922): Das Diluvium des unteren Unstruttales von Sömmerda bis zur 
Mündung. - Jb. Hallesch. Verb., N.F., 3: 89-124; Halle.

LožEK, V. (1964): Die Quartärmollusken der Tschechoslowakei. - Rozpravy UUG, 31: 374 S.; Praha.

LožeK, V. (1989): Zur Stratigraphie des ElsterHolstein-Saale-Komplexes in der Tschechoslowakei. - EAZ Ethnogr.-Archäol. Z., 30: 579-594; Praha.

Mania, D. (1973): Paläoökologie, Faunenentwicklung und Stratigraphie des Eiszeitalters im mittleren Elbe-Saalegebiet auf Grund von Molluskengesellschaften. - Geologie, 21, Beih. 78/79: 175 S.; Berlin.

Mania, D. \& Altermann, M. (1970): ): Zur Gliederung des Jung- und Mittelpleistozäns im mittleren Saaletal bei Bad Kösen. - Geologie, 19: 1161-1184; Berlin.

Mania, D. \& MaI, D.-H. (2001): Molluskenfaunen und Floren im Elbe-Saalegebiet während des mittleren Eiszeitalters. - Praehistoria Thuringica, 6/7: 46-91; Artern.

Maul, L. C. (2002): The Quaternary small mammal faunas of Thuringia (Central Germany). - In: Meyrick, R. A. \& Schreve, D. C. (eds.): The Quaternary of Central Germany. Field Guide. Quaternary Research Association: 79-95; London.

Maul, L. C., Rekovets, L., Heinrich, W.-D., Keller, T. \& Storch, G. (2000): Arvicola mosbachensis (SCHMIDTgEN 1911) of Mosbach 2: a basic sample for the early evolution of the genus and a reference for further biostratigraphical studies. - In: STORCH, G. \& Weddige, K. (eds.): Advances in Vertebrate Palaeontology. - Senckenb. Lethaea, 80: 129-147; Frankfurt a. M.

Meijer, T. \& Preece, R. C. (2000): A review of the occurrence of Corbicula in the Pleistocene of North-West Europe. - Geologie en Mijnbouw / Netherlands Journal of Geosiences, 79: 241-255; Utrecht.

Meng, S. (1995): Die Mollusken der WeichselKaltzeit von Erfurt (Thüringen). - Veröffent- lichungen des Naturkundemuseums Erfurt, 14: 150-167; Erfurt.

Meng, S. (1998): Mollusken (Schnecken und Muscheln) aus jungpleistozänen Geraschottern von Arnstadt-Rudisleben (Thüringen). - Veröffentl. Naturhist. Mus. Schloß Bertholdsburg Schleusingen, 13: 37-42; Schleusingen.

Meyrick, R. (2002): Bedeutende Fossilvorkommen des Quartärs in Thüringen. Teil 2: Mollusken. - Beitr. Geolog. Thüringen, N.F., 9: 145-172; Jena.

MüNZING, K. (1968): Molluskenfaunen aus altpleistozänen Neckarablagerungen. - Jb. Geol. Landesamt Baden-Württemberg, 10: 105-119; Freiburg im Breisgau.

MüNZING, K. (1969): Quartäre Mollusken aus dem Kaiserstuhl. - Jb. Geol. Landesamt Baden-Württemberg, 11: 87-115; Freiburg im Breisgau.

Naumann, E. \& Picard, E. (1909): Weitere Mitteilungen über das diluviale Flußnetz in Thüringen. - Jb. Kgl. Preuß. Geol. Landesanstalt 1908, 29: 566-588; Berlin.

Prenzel, H. (1967): Feinstratigraphische Untersuchungen im Tertiär und Pleistozän des Tagebaues Rossbach. - Diplomarbeit, Geol.- Paläont.-Institut, Universität HalleWittenberg (unveröff.).

RäHLE, W. (1977): Die Mollusken der Burghöhle Dietfurt. - In: Brunnacker, K. et al. (Hrsg.): Der Übergang vom Pleistozän zum Holozän in der Burghöhle von Dietfurt bei Sigmaringen. - Kölner Jb. für Vor- und Frühgeschichte, 15 (1975-1977): 112-122; Berlin.

Rähle, W. \& Bibus; E. (1992): Eine altpleistozäne Molluskenfauna in den Höhenschottern des Neckars bei Rottenburg, Württemberg. - Jb. Geol. Landesamt Baden-Württemberg, 34: 319-341; Freiburg im Breisgau.

Ruske, R. (1961): Die Gliederung des Pleistozäns im Geiseltal und in seiner Umgebung. - Geologie, 10: 152-168; Berlin. 
Ruske, R. (1964): Das Pleistozän zwischen Halle (Saale), Bernburg und Dessau. - Geologie, 13: 570-597; Berlin.

Ruske, R. (1973): Stand der Erforschung des Quartärs in den Bezirken Halle und Magdeburg. - Z. geol. Wiss., 1: 1065 - 1086; Berlin.

Ruske, R. \& WÜnsche, M. (1961): Löße und fossile Böden im mittleren Saale- und unteren Unstruttal. - Geologie, 10: 9-29; Berlin.

Ruske, R. \& Wünsche, M. (1964): Zur Gliederung des Pleistozäns im Raum der unteren Unstrut. - Geologie, 13: 211-222; Berlin.

S̈̈NGER, G. (1928): Über glaziale Einlagerungen in der Saalehauptterasse der Umgebung von Weißenfels. - Beitr. Geol. Thüringen, 1: 1-24; Jena.

Schmierer, T. (1922): Beitrag zur Kenntnis des faunistischen und floristischen Inhalts der Berliner Paludinenbank. - Z. dt. geol. Ges., 74: 207-236; Berlin.

Schulz, W. (1962): Gliederung des Pleistozäns in der Umgebung von Halle (Saale). - Geologie, 11, Beih. 36: 1-69; Berlin.

Siegert, L. \& Weissermel, W. (1911): Das Diluvium zwischen Halle a. S. und Weißenfels. - Abh. Kgl. Preuß. Geol. Landesanst., NF, 60: 351 S.; Berlin.

STEINMÜller, A. (1976): Lithofazieskarten Quartär 1: 50 000, Blatt 2664 Weißenfels. - Zentr. Geol. Inst.; Berlin.

SteinmülleR, A. (1980): Lithofazieskarten Quartär 1:50 000, Blatt 2564 Halle/Saale S. - Zentr. Geol. Inst.; Berlin.

Steinmüller, A. (1982): Die stratigraphische Einstufung der pleistozänen Schichtenfolge und des Clactoniens von Wangen im unteren Unstruttal. - Z. geol. Wiss., 10: 745758; Berlin.

Steinmüller, A. (I998): Sedimentologie, stratigraphische Gliederung sowie Lagerungsformen der präglazialen Ablagerungen und zur Flußgeschichte von Helme und Unstrut im Auslaugungsgebiet zwischen Kyffhäuser und Nebraer Pforte. - Geowiss. Mitt. v. Thüringen, Beih. 7: 1-61, Weimar.

Toepfer, V. (1935): Die mitteldiluvialen Säugetierreste aus der Saaleterrasse bei Lengenfeld-Bad Kösen. - N. Jb. Min., Geol., Pal., Abt. B, Beil.-Bd., 74: 60-88; Stuttgart.

Urban, B., Lenhard, R., Mania, D. \& ALBRECHT, B. (1991): Mittelpleistozän im Tagebau Schöningen, Ldkr. Helmstedt. - Z. dt. geol. Ges., 142: 351-372, Hannover.

Urban, B., Thieme, H. \& Elsner, H. (1988): Biostratigraphische, quartärgeologische und urgeschichtliche Befunde aus dem Tagebau "Schöningen", Ldkr. Helmstedt. - Z. dt. geol. Ges., 139: 123-154; Hannover.

Walter, H. \& Suhr, P. (1998): Lebensspuren aus kaltzeitlichen Bändersedimenten des Quartärs. - Abh. Staatl. Mus. Mineral. Geol. Dresden, 43/44: 311-328; Dresden.

Weber, T., Litt, T. \& Schäfer, D. (1996): Neue Untersuchungen zum älteren Paläolithikum in Mitteldeutschland. - Terra \& Praehistoria, Beitr. z. Ur- und Frühgeschichte Mitteleuropas, 9 (Festschr. f. Klaus-Dieter Jäger): 13-39; Wilkau-Hasslau.

Weiss, A. (1899): Die Conchylienfauna der Kiese von Süssenborn bei Weimar. - Z. dtsch. geol. Ges., 51: 156-167; Berlin.

WeIsSERMEL, W. (1908): Erläuterungen zur Geologischen Karte von Preußen und benachbarten Bundesstaaten, Lieferung 146, Blatt Weißenfels. - Kgl. Preuß. Geol. Landesanst.; Berlin.

Woldstedt, P. (1950): Norddeutschland und angrenzende Gebiete im Eiszeitalter. - 464 S.; Stuttgart (Koehler).

WÜsт, E. (1901 a): Untersuchungen über das Pliozän und das älteste Pleistozän Thüringens nördlich vom Thüringer Walde und westlich der Saale. - Abh. Naturforsch. Ges. Halle, 23: 17-369; Stuttgart.

Wüst, E. (1901 b): Ein fossilführender Saalekies bei Uichteritz bei Weißenfels. - Z. f. Naturwissenschaften, 74: 65-71; Halle. 
ZÁruba, Q., KukLa, J. \& LožEK, V. (1962): Die telpleistozänen Ilmablagerungen von Süßenaltpleistozänen Ablagerungen in Žalov bei Prag. born bei Weimar. - Paläontologische Abh., Abt. - Anthropozoikum, 10 (1960): 1-162; Praha. A, Paläozoologie, 3: 415-461; Berlin.

Zeissler, H. (1969): Konchylien aus den mit- 